SC-M-72 0076

JULY 1972

TRANSPORTATION SHOCK AND VIBRATION DESCR IPTIONS FOR PACKAGE DESIGNERS
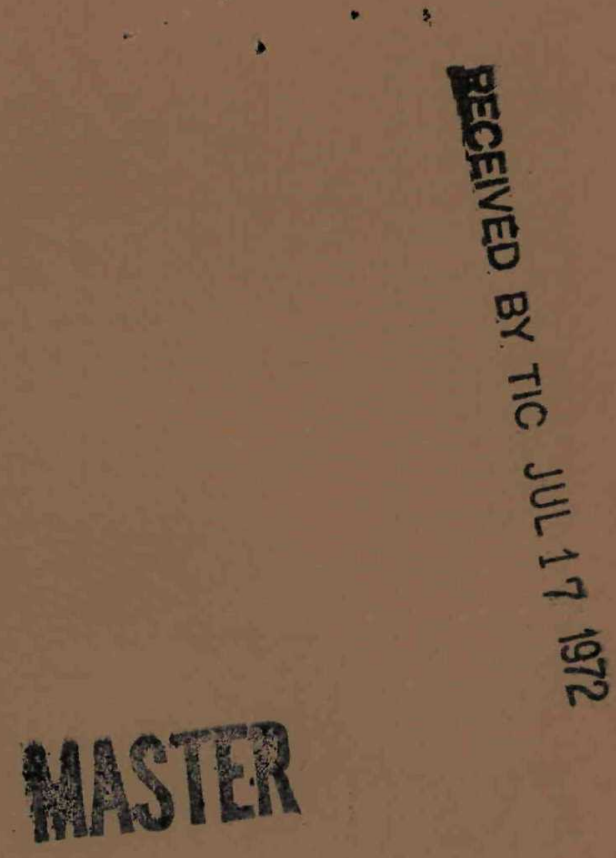

J. T. Foley

Criteria and Heat Transfer Division

Sandia Laboratories, Albuquerque 
Issued by Sandia Corporation,

a prime contractor to the United States Atomic Energy Commission

\section{NOTICE}

This report was prepared as an account of work sponsored by the United States Government. Neither the United States nor the United States Atomic Energy Cornmission, nor any of their employees, nor any of their contractors, subcontractors, or their employees, makes any warranty, express or implied, or assumes any legal liability or responsibility for the accuracy, completeness or usefulness of any information, apparatus, product or process disclosed, or represents that its use would not infringe privately owned rights. 


\section{DISCLAIMER}

This report was prepared as an account of work sponsored by an agency of the United States Government. Neither the United States Government nor any agency Thereof, nor any of their employees, makes any warranty, express or implied, or assumes any legal liability or responsibility for the accuracy, completeness, or usefulness of any information, apparatus, product, or process disclosed, or represents that its use would not infringe privately owned rights. Reference herein to any specific commercial product, process, or service by trade name, trademark, manufacturer, or otherwise does not necessarily constitute or imply its endorsement, recommendation, or favoring by the United States Government or any agency thereof. The views and opinions of authors expressed herein do not necessarily state or reflect those of the United States Government or any agency thereof. 


\section{DISCLAIMER}

Portions of this document may be illegible in electronic image products. Images are produced from the best available original document. 


\title{
TRANSPORTATION SHOCK AND VIBRATION DESCRIPTIONS FOR PACKAGE DESIGNERS
}

\author{
J. T. Foley \\ Criteria and Heat Transfer Division 1543 \\ Sandia Laboratories \\ Albuquerque, New Mexico 87115
}

NOTICE

Printed

July 1972

This report was prepared as an account of work sponsored by the United States Government. Neither the United States nor the United States Atomic Energy Commission, nor any of their employees, nor any of their contractors, subcontractors, or their employees, makes any warranty, express or implied, or assumes any makes any warranty, express or implied, or assumes any legal liability or responsibility for the accuracy, completeness or usefulness of any information, apparatus, product or process disclosed, or represents
would not infringe privately owned rights.

\section{ABSTRACT}

This report is a composite record of two talks given on the subject of "Transportation Shock and Vibration Descriptions for Package Designers."

The first talk was given, as indicated in the introduction, at a technical institute course at the University of Wisconsin in December 1971.

The second talk was given at a Westinghouse Corporation Packaging Seminar held at the Westinghouse Defense and Space Division, Baltimore, Maryland, February 15, 1972.

The figures used in this report are the ones used for illustrative purposes in the presentations. The engineering descriptions of the envrionment models discussed are published in a paper entitled "Current Predictive Models of the Dynamic Environment of Transportation." This paper was published in the Proceedings of the Institute of Environmental Sciences on May 5, 1972 and is included herein as an Appendix with IES permission. 
$\bullet$ 


\section{CONTENTS}

\section{Page}

Introduction

Text of Remarks on Transportation Shock and Vibration Descriptions for Package Designers

Summary

32

References

Appendix 
• 


\section{TRANSPORTATION SHOCK AND VIBRATION DESCRIPTIONS \\ FOR PACKAGE DESIGNERS}

Introduction

This report is the text of a presentation made on November 30,1971, at the University of Wisconsin, Madison, Wisconsin.

This presentation was one of several centered about the theme, "Packaging: Transportation, Handling and Storage Environment."

The pattern of these presentations was as follows:

I. "Definition of Terms Pertaining to Transportation, Handling and Storage, " by W. D. Godshall, Forest Products Laboratory, Madison, Wisconsin.

II. Shock and Vibration Encountered in Various Modes of Transportation--for:

A. Aircraft, Trucks, and Ships by J. T. Foley, Sandia Laboratories, Albuquerque, New Mexico;

B. Rail roads by W. Silver, Westinghouse Corporation, Baltimore, Maryland

III. "Handling Before and After Transportation, " by J. L. Hicks, Illinois Central Rail road Company.

IV. "Atmospheric and Port Handling Facilities of the Major Ports Throughout the World, "by H. Saffer, Fireman's Fund American Insurance Companies, New York.

V. "Economical and Efficient Package Design Attained only if All Hazardous Elements of Your Distribution System Are Known, "by J. Winne, Westinghouse Electric Corporation, Pittsburg, Pennsylvania.

VI. "The Use of Laboratory Equipment to Simulate Specific Hazards Encountered in Shipping, Handling, and Storage, "by C. Gaynes, Gaynes Testing Laboratories, Chicago, Illinois.

VII. "Various Types of Shock and Vibration Isolators Used for Protection of Articles During Shipment, "by J. Hardigg, Hardigg Industries, Inc., Deerfield, Massachusetts. 
VIII. "Interaction Between Compressive Strength of Corrugated Containers and the Effects of: Stacking, Moisture Conditions, Contents, Bearing Surfaces, "by K. Q. Kellicutt, University of Wisconsin, Madison, Wisconsin.

This report was prepared in response to requests for the material presented in II A and to serve as a permanent record of the presentation. 
Text of Remarks on

TRANSPORTATION SHOCK AND VIBRATION DESCRIPTIONS FOR PACKAGE DESIGNERS

\section{Acknowledgments}

The material herein described was obtained over the last 10 years and is the result of work done by several people at Sandia, particularly M. B. Gens, R. A. Harley, C. F. Magnuson, and the author. 


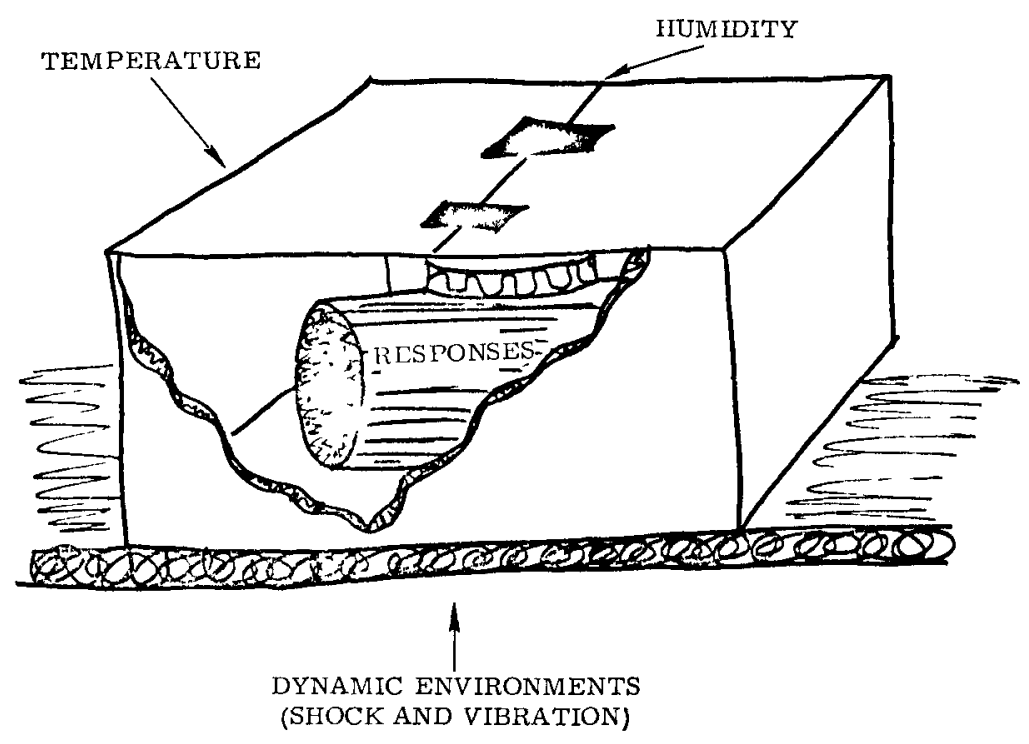

Figure 1. Inputs and Responses

Introduction

Modern methods of measuring several environments in research-oriented transportation tests, and outlined techniques whereby the data so obtained could be reduced and interpreted are provided in Reference 1. This reference illustrated that two characteristics of a packaging system can be measured: inputs to, and responses of, a package system.

This text concentrates on describing the source, character, and intensity of only one environmental "input" to cargo, the dynamic environment, or as some call it, the shock and vibration environment. 


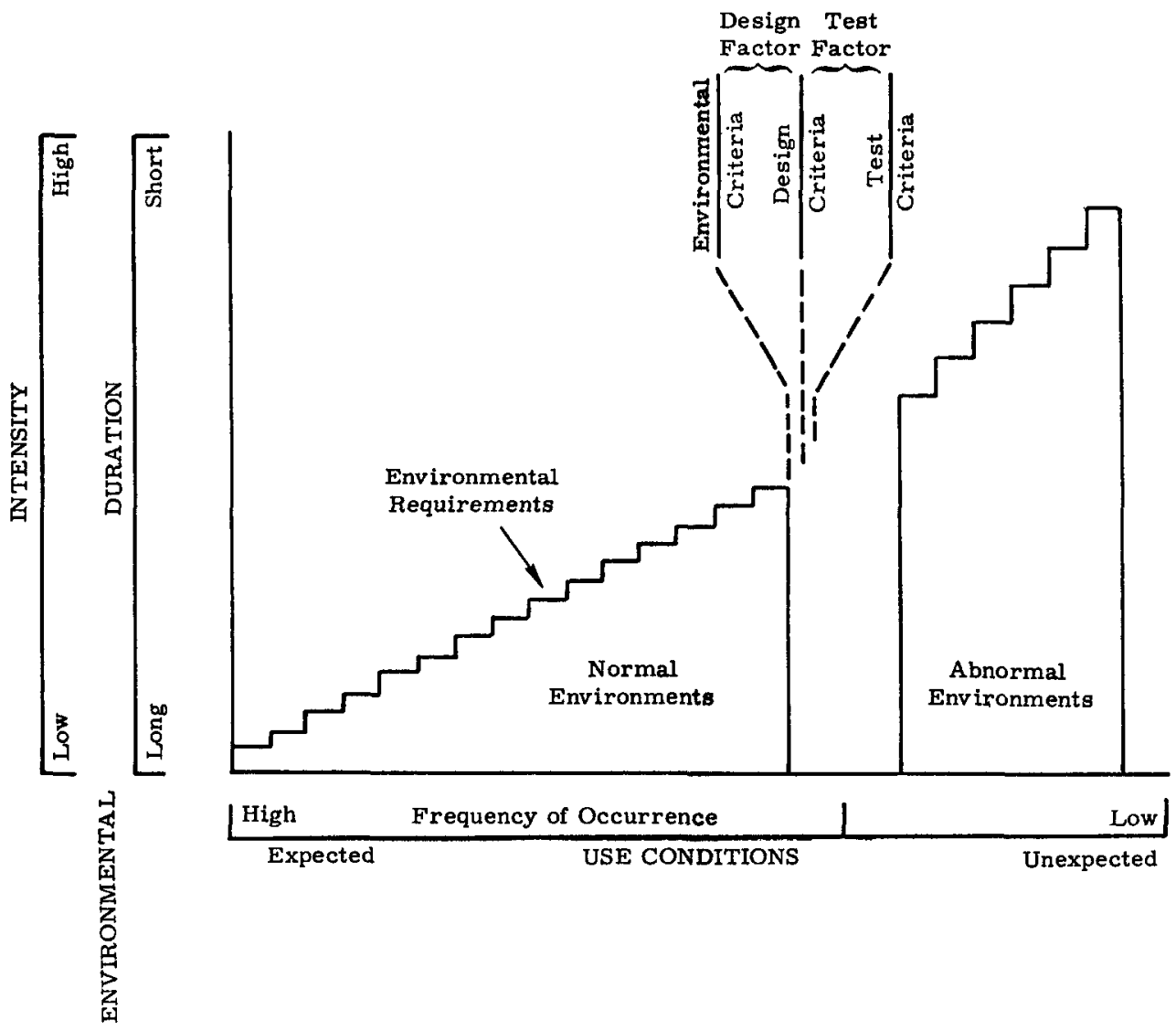

Figure 2

A simplified picture of a philosophy of design and test criteria derivation is illustrated in Figure 2. For a given package the maximum expected environment criterion is determined, a margin, called a design factor, is applied to this description to obtain a design criterion, and a further margin, called a test factor, may be applied to derive a test criterion. What is not evident in this simplified picture, is that the manner in which the input environment is described to arrive at the test criterion can differ considerably from the manner in which the environment is described to determine what form the design should take, or to evaluate a particular package systems design margin. 
Repetitive, but not necessarly steady state. More akin to shock environment than vibration in truck, traller, and tracked vehicles.
Ships. Military and commercial

Planes. Military and commercial

Trucks: Military and commercial, off and on road

Trallers: Military and commercial, off and on road

Trains: Foreign and domestic

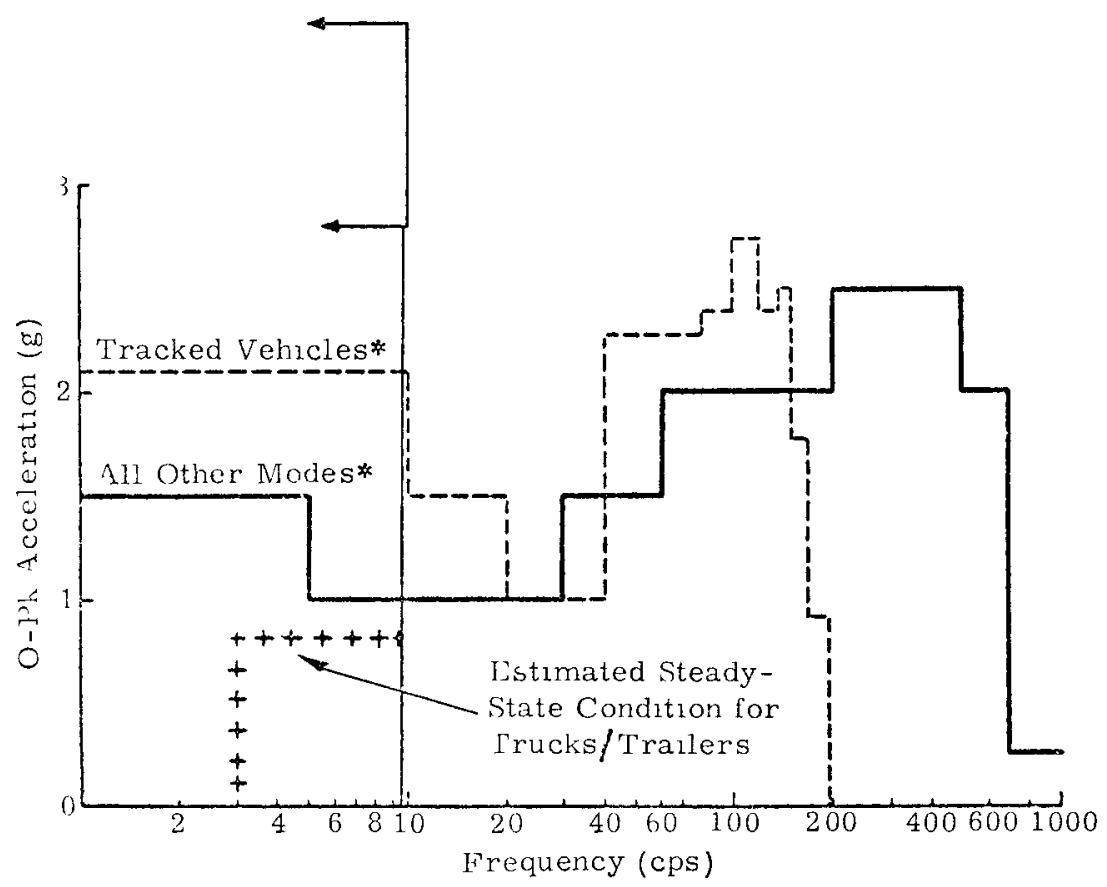

Figure 3. Envelope of Extreme Vibration Environment Experienced by Cargo in All Modes of Transport

Figure 3 shows an environment "picture." The ordinate is in 0- Pk G, the abscissa is frequency in cycles/second. It is an envelope of all input peak accelerations that had been measured in all transport modes on the cargo floor of carriers regardless of the axis in which they occurred. The environment is called vibration, implying that this is the type of test machine that could be used. Here, however, is a warning note that indicates that below $10 \mathrm{cps}$ use of a shock test machine might be necessary, but there is no indication in this description as to what shock levels the shock machine may be required to deliver.

With the ordinate given in $0-\mathrm{Pk}$ acceleration, the implication is that the test machine should produce sinusoidal motion at $\mathrm{g}$-levels shown for each frequency.

Th1s was an environmental picture derived in 1964, based upon the state of the art of field test instrumentation, data reduction/interpretation techniques, and the then-current capabilities of laboratory test equipment 


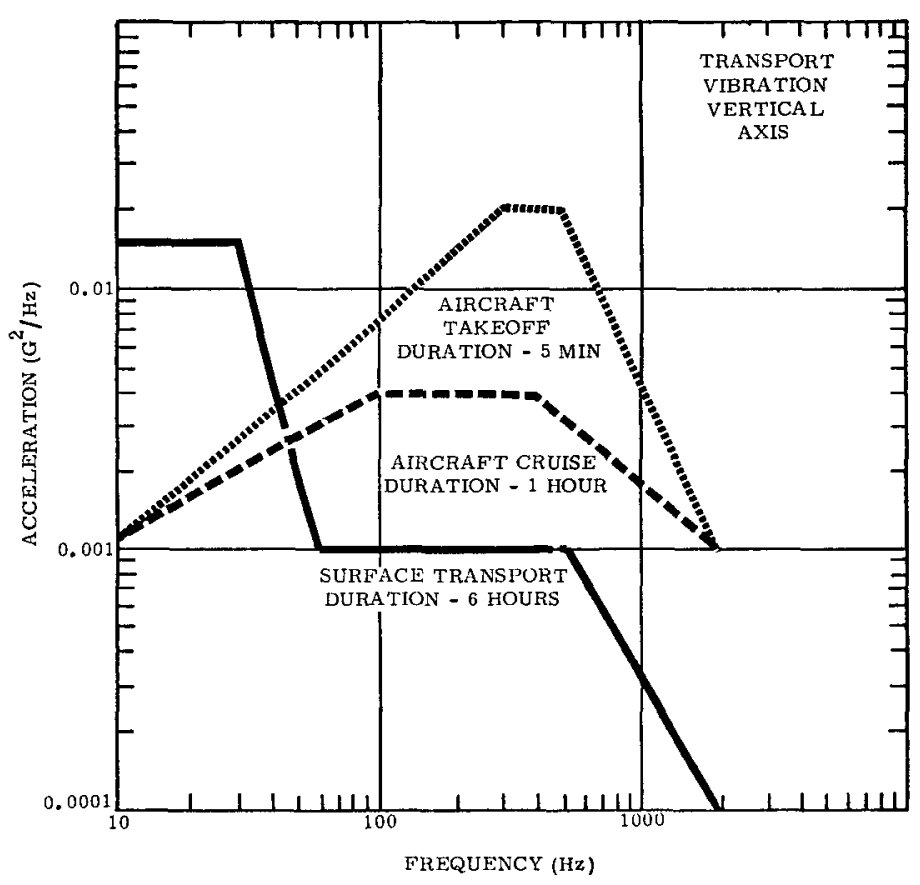

Figure 4

In applying new techniques to field test research data obtained since 1964 and taking into consideration the capabilities of modern-day test equipment, Figure 4 is a more recent experiment in describing the same environments shown previously but still slanted primarily towards use by test developers. Here are some of the features of this experimental description.

1. The title "transport vibration" identifies the environment described and the type of test machine that could be used.

2. The second title line indicates that this is a description of data obtained in only one axis, the vertical axis of the transport modes.

3. The transport modes have been separated into surface and air transport, and the air transport mode has been further separated into two events, takeoff and cruise. The shapes of the curves and durations listed give a clue as to the reason, showing that there is a definite difference in intensity with frequency location in each mode of transport, and a definite difference in duration expected for some events in air transport, and a different duration expected in regard to surface and air transport.

4. The frequency range over which the environment is described is much wider than the older description, now extending to $2000 \mathrm{~Hz}$. 
5. Note the ordinate term; it is no longer $0-\mathrm{PkG}$, but is now $\mathrm{G}^{2} / \mathrm{Hz}$. This is a major change, not like the $\mathrm{Hz}$ vs cps one. It tells a test deriver that the environment is not a simple sine-wave motion at each discrete frequency, but that it varies in amplitude with time, and further, that its variation follows a pattern that can be described by a shaped Gaussian random amplitude distribution. 
There are three questions which a packaging engineer may be attempting to answer when applying transportation dynamic environment descriptions to evaluate the response of a particular packaging system.

1. Does the package protect the contained item?

2. Is the package strong enough to withstand the environments?

3. Is the tiedown system strong enough to keep the package on the vehicle?

These three questions, in effect, describe the transport-packaging problem as one of systems analysis, wherein the package, the product within the package, and the means by which the package is retained on the transporting vehicle are the component parts of the packaging system. 


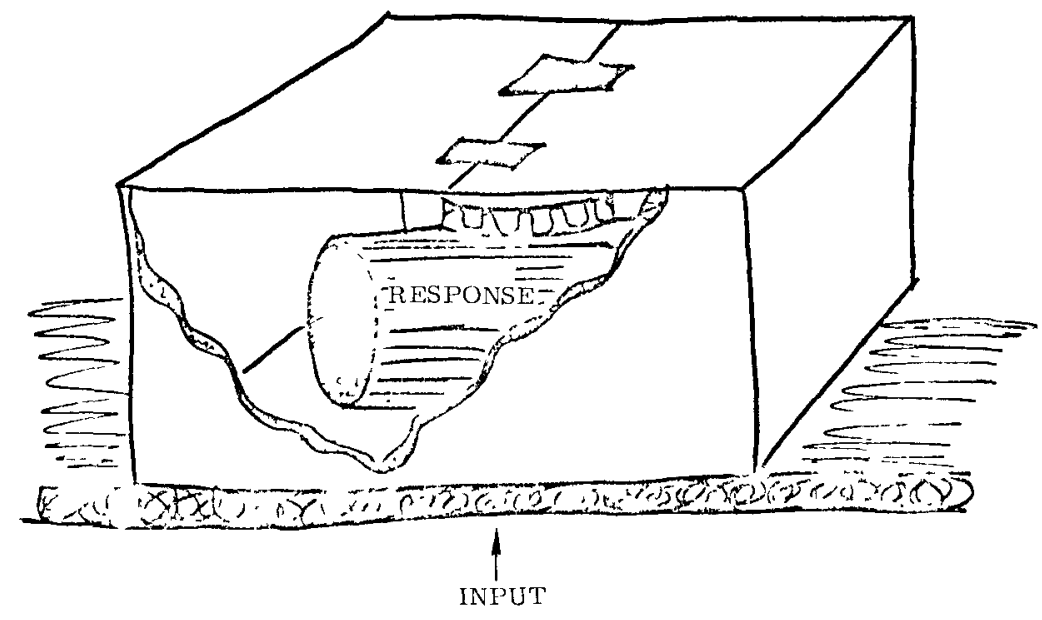

Figure 5. Inputs and Responses

Two basic environment characteristics of a packaging system of concern to a package designer are those of inputs to, and responses of, the system. Input is defined as the environment acting at the interface of the transporting vehicle and the system. Response is defined as the environment within the package, and is, quite often, the response of the packaged product. These are illustrated in Figure 5.

However, a few anomalies plague designers. One such anomaly was that some packages designed to withstand some inputs were arriving at their destination intact, but the contents within the package were smashed!

It was found, in many instances by packaging engineers, that the answer to the problem of having a package arriving intact, and yet containing a broken product was to suspend the product within the package in some resiliant material in some cases, and in others by holding the product very rigidly to the floor of a vehicle without a package. 


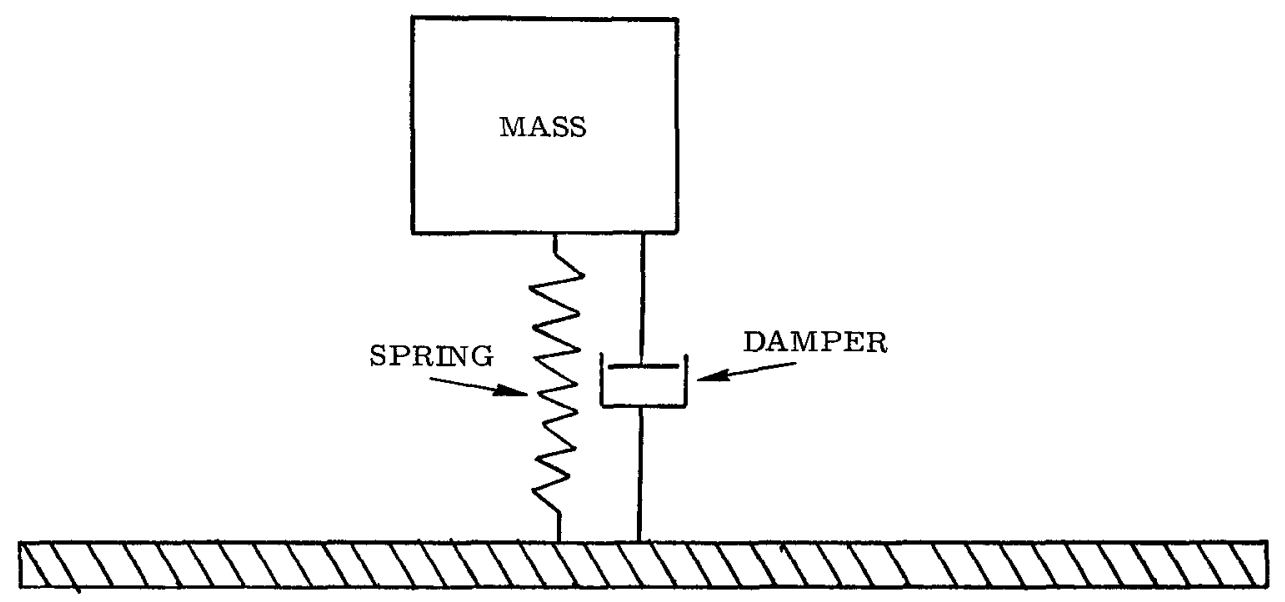

Figure 6. Spring-Mass-Damper Combination

The preceding gives rise to the concept that a packaging system design should not be based on the assumption that it is a solid weight but that, at the very least, it should be viewed as a weight and a spring (as shown in Figure 6), and in some cases, several weights and springs hooked together. It is further determined that the concept of a damping mechanism must be added. With the evolution of the spring-mass-damper combination concept for evaluating the response of a given package system design, package engineers began to ask for environmental "input" descriptions which would permit them to use the tools that were now available to them for design analysis.

To apply the spring-mass damper concept in design analysis, three things must be available:

1. Detailed knowledge and experience in applying the various analytical and interpretive tools that the spring-massdamper concept makes available.

2. Detailed knowledge of the failure modes of the packaged item (fragility).

3. Environment "input" descriptions for each of the transport modes in which the package will be shipped.

The two basic environment parameters which can be measured in field experiments are intensity and time. Through the application of various types of instrumentation and data reduction techniques, these basic parameters can be presented in many different forms. In the case of the dynamic environment descriptions which follow, most of the intensities will be some form of vehicle bed motion in engineering units of acceleration, and in the time domain, the durations of these accelerations will be presented in increments ranging from seconds to milliseconds. 

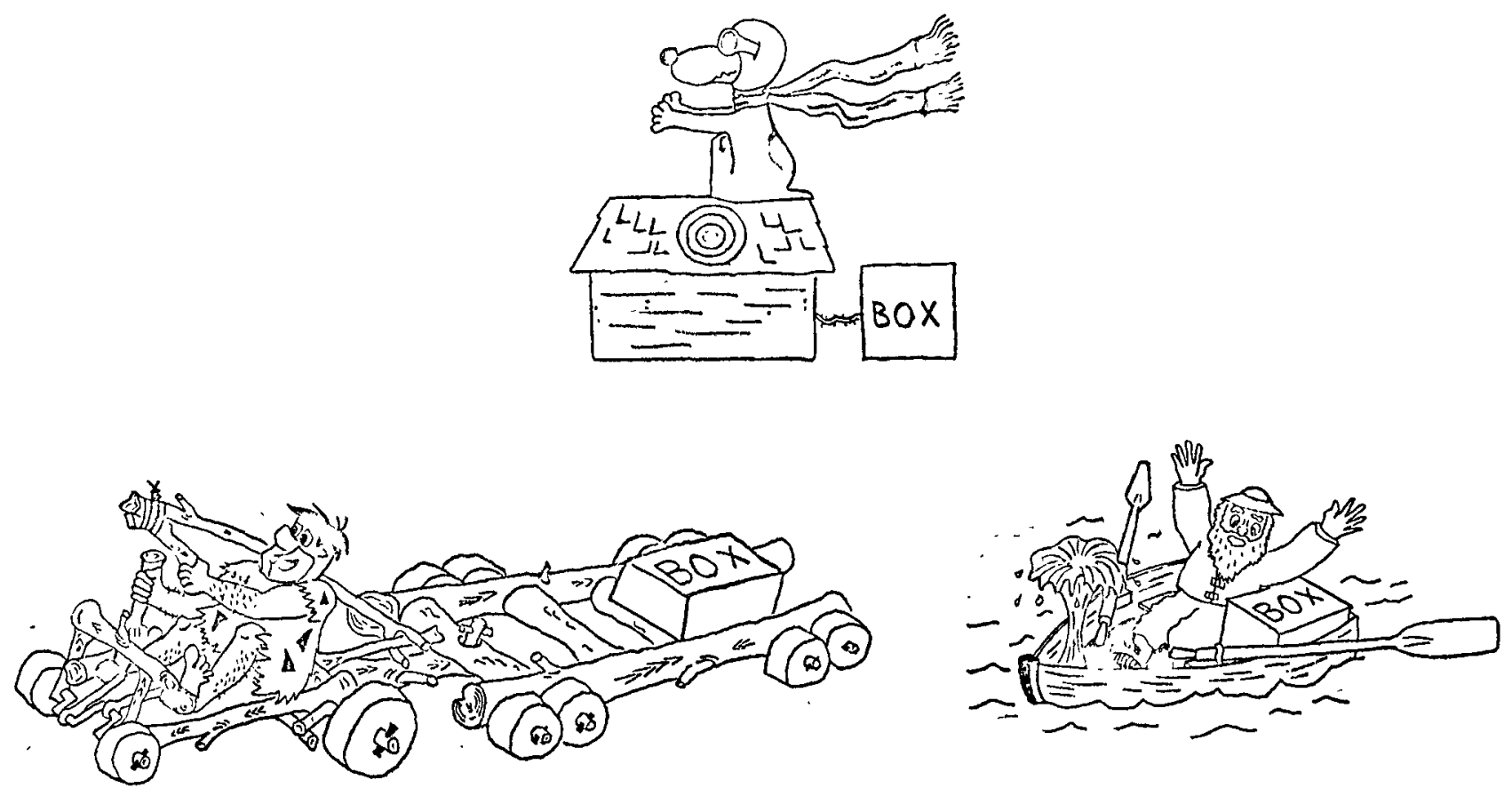

Figure 7. Transport Modes

Figure 7 shows the modes of transport discussed. More time was allotted to developing the background of the environment description for trucks since it is a more universally known vehicle type to most people. The other modes are discussed in less detail, for the method of development of the descriptions for all the modes is essentially the same. 


\section{CONDITION A \\ UNLOADED TRUCK TRAVEL ON CONCRETE \\ HIGHWAY AT HIGH SPEED}

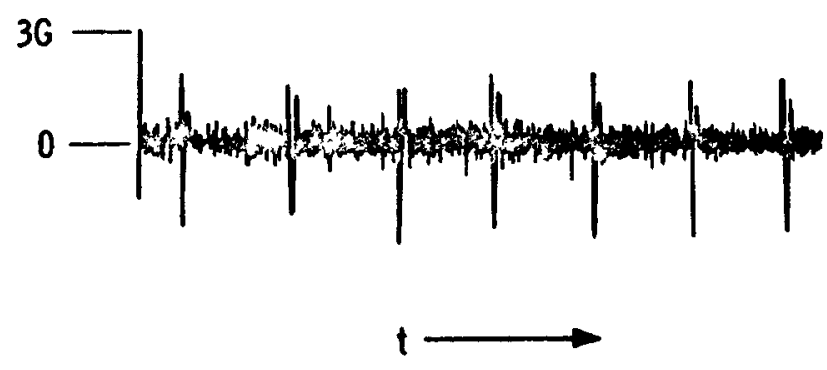

CONDITION B

UNLOADED TRUCK TRAVEL ON BLACKTOP HIGHWAY AT LOW SPEED

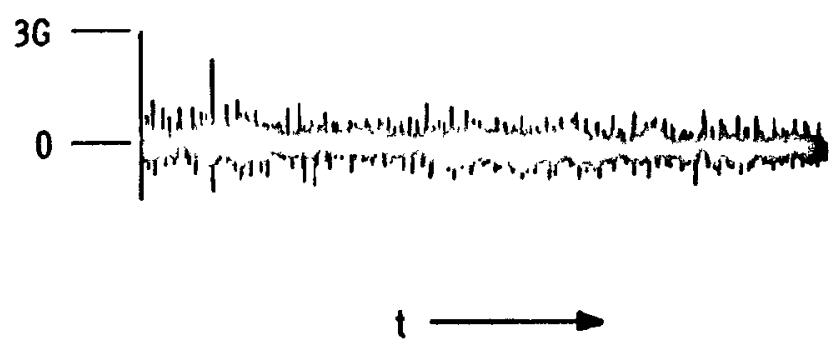

Figure 8. Examples of Oscillograph Traces

In Figure 8 are a pair of acceleration-time histories obtained from an accelerometer during truck transport. In Condition B, taken on smooth blacktop, note that for over the majority of the time trace shown here, the character of the environment is relatively uniform.

Note, however, that once during this period something different happened. It has been determined that this is due to a new event occurrence, where, while on the blacktop, the truck hits things like a pothole, a crack in the road, or a patch. Note that this happened only once during this time span.

In the other time history, taken on a concrete highway, the most immediately evident thing about this situation is that in the same period of time of travel as on blacktop, bumps occur more often. This may be recognized as the truck going over expansion joints in the highway.

Observe what goes on in between the times the truck hits the expansion joints, and grossly compare this activity to the activity that went on after the truck on blacktop hit that pothole--it is quite similar.

Figure 8 illustrates the methods used in environmental descriptions of late, and that is to describe the input environment as being composed of two basic kinds of events. 
As can be seen from the time-histories in the truck mode of transport (Figure 8), it is found for the most part, that both the recurrent and intermittent types of short term events occur concurrently with the long term background. Some exceptions identified to date are the events wherein a truck backs into something like a loading dock, or stops prior to crossing railroad tracks.

By way of comparison regarding another mode of transport in this respect, ship transport is quite similar, wherein the source of the recurrent short term environment is produced by the ship slamming in heavy seas, and the intermittent environment is produced when beaching or docking. 


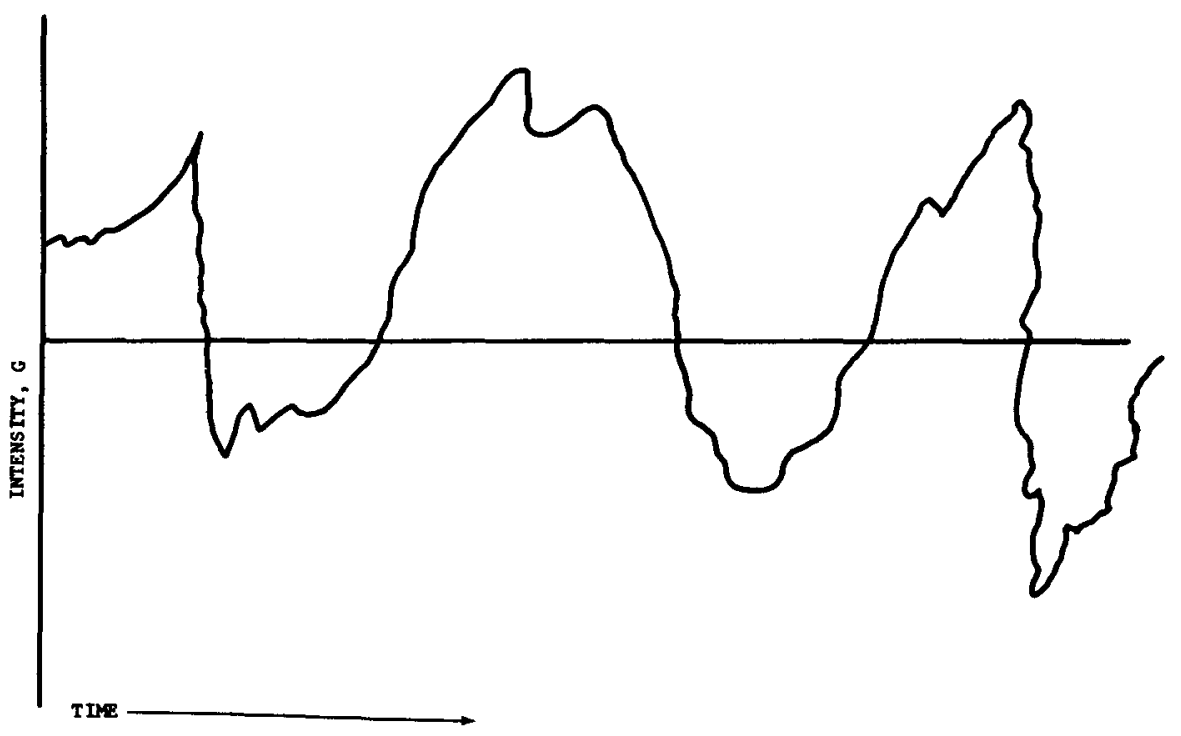

Figure 9

Figure 9 is the sort of G-time history one sees when he looks at that long-term signal close up. It doesn't look smooth, does it? Here is one method of explanation: 


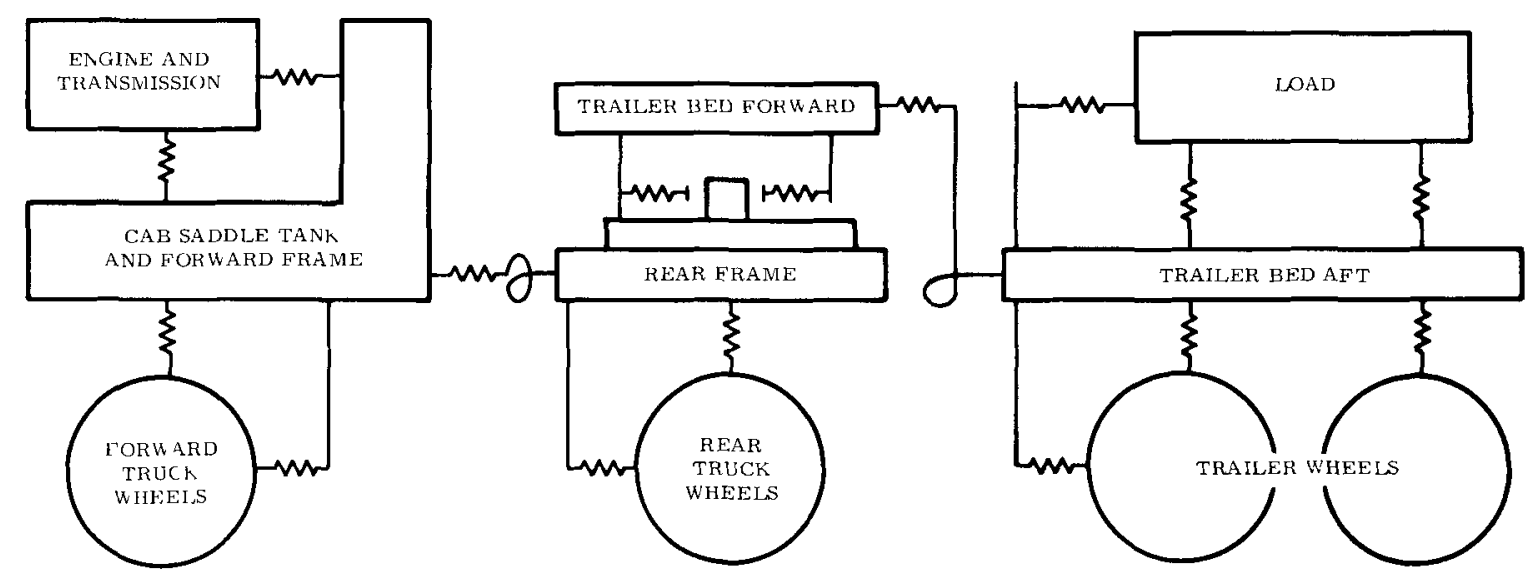

Figure 10. The Vehicle

In a manner similar to what was discussed with regard to evaluating a package system, the vehicle itself can be visualized as being a collection of springs and masses all connected together (Figure 10). Now each one of these springs and masses can be thought of as being a bell, or one note struck on a piano. For example, say one of these spring-mass subsystems is the mass and stiffness of one wheel and tire combination. Theory and experiment had demonstrated that if you apply a displacement to this subsystem, it will oscillate or "vibrate" at a single frequency. This frequency is called the natural frequency of that part.

This is why the accelerometer trace in Figure 9 is jagged--one is looking at the resultant frequency contribution of all the various parts of the vehicle. 


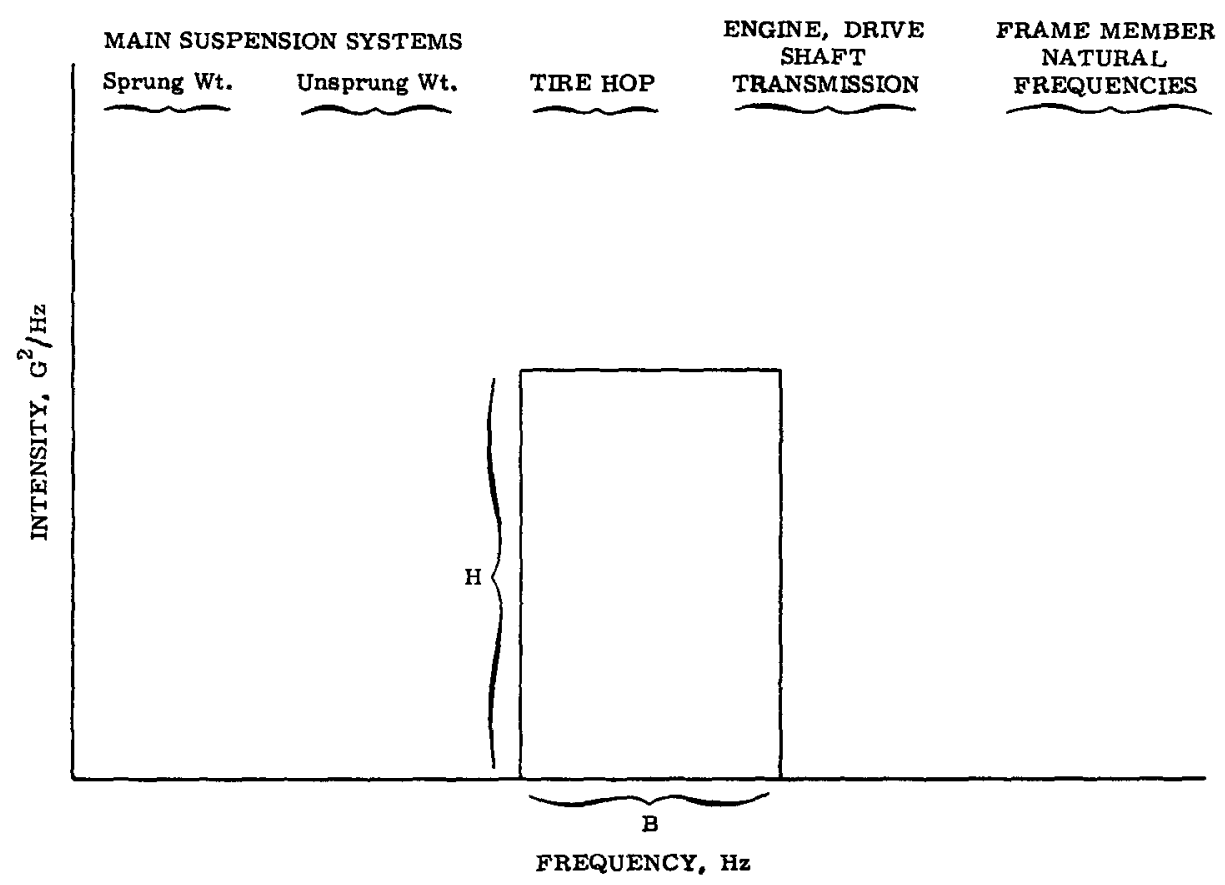

Figure 11. Frequency Band Widths

How can this environment be described? The first step in the procedure is to break up this time history through a data analysis system, and show it as the acceleration intensity that is being contributed by each of the component parts of the vehicle, this is the environment intensity versus frequency picture of the environment that has been shown for many years.

This would be an adequate description if all trucks were about the same, but they are not, so one must go further. In Figure 11, the component parts of the truck that are related to these frequencies are identified. They are shown over brackets because it has been found that there is a range of frequency variation in these sources from one truck of the same type to the next, from one type of truck to the next, from the amount of vehicle wear, etc.

About intensity description--over a variety of truck types, road types, cargo loads, vehicle speeds, etc.. it has been found that the peak acceleration within frequency band compartments such as are illustrated here vary from one time to the next, in an irregular manner. One fortunate thing about this is that although irregular in terms of how many G's may be present at any given instant of time during truck travel, some statements can be made as to the probability that certain Pk Gvalues may occur. The bases for deriving such an intensity description are extremely complicated, but briefly, this is how it was done: The approach taken to obtain such prediction pictures is similar to the techniques used by poll-takers predicting election outcomes or poll-taking to estimate what percentage of the viewing public is watching a particular television program, i.e., sampling the environment, and building from this sampling technique a "picture" of what the environment looks like. "Pictures," so obtained are called predictive models of the environment.

They offer the advantage of being economically feasible to obtain; it is possible to revise them whenever additional data are obtained; and provide a baseline, or comparison criterion, for any new data on a specific vehicle. 


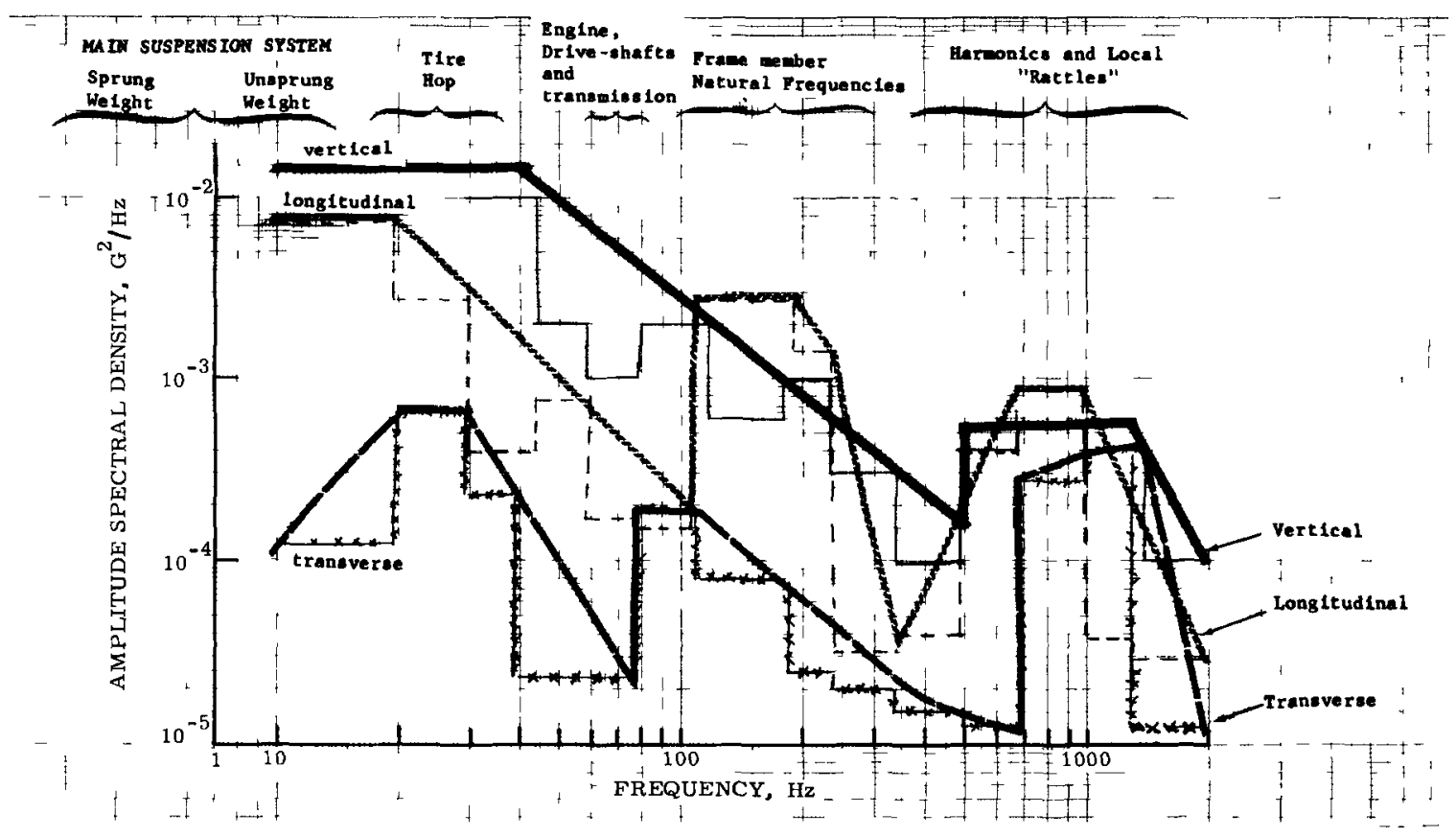

Figure 12. Truck Transport

Figure 12 shows such an environment model for long-term events in truck transport. The environmental data used in deriving this picture includes the following:

Truck Types Included

1. Well-used tractor - flatbed trailer system with leaf-spring suspension.

2. Renewed tractor - flatbed trailer system with leaf-spring suspension.

3. Well-used tractor - van trailer system, air ride suspension.

4. New tractor - van trailer system, air ride suspension.

5. Carefully driven tractor - van trailer system, leaf-spring suspension.

6. 2-1/2 ton flatbed truck, conventional commercial design.

7. 2-1/2 ton van truck, special design for transporting explosives.

Load Ranges Included
1. Empty (type 1,2)
4. 2-3000 pound load (type $3,4,5$ )
2. 600 pound load (type 6)
5. 30,000 pound load (type 1,2 )

3. 1200 pound load (type 7) 
Indicated behind the smooth trend-lines are the bands which illustrate the frequency-band compartments referred to earlier. Note the data begins at $10 \mathrm{~Hz}$. The long-term motion is not significant below $10 \mathrm{~Hz}$, and the significant environment in this frequency range is produced by the short term intermittent and recurrent environments. 


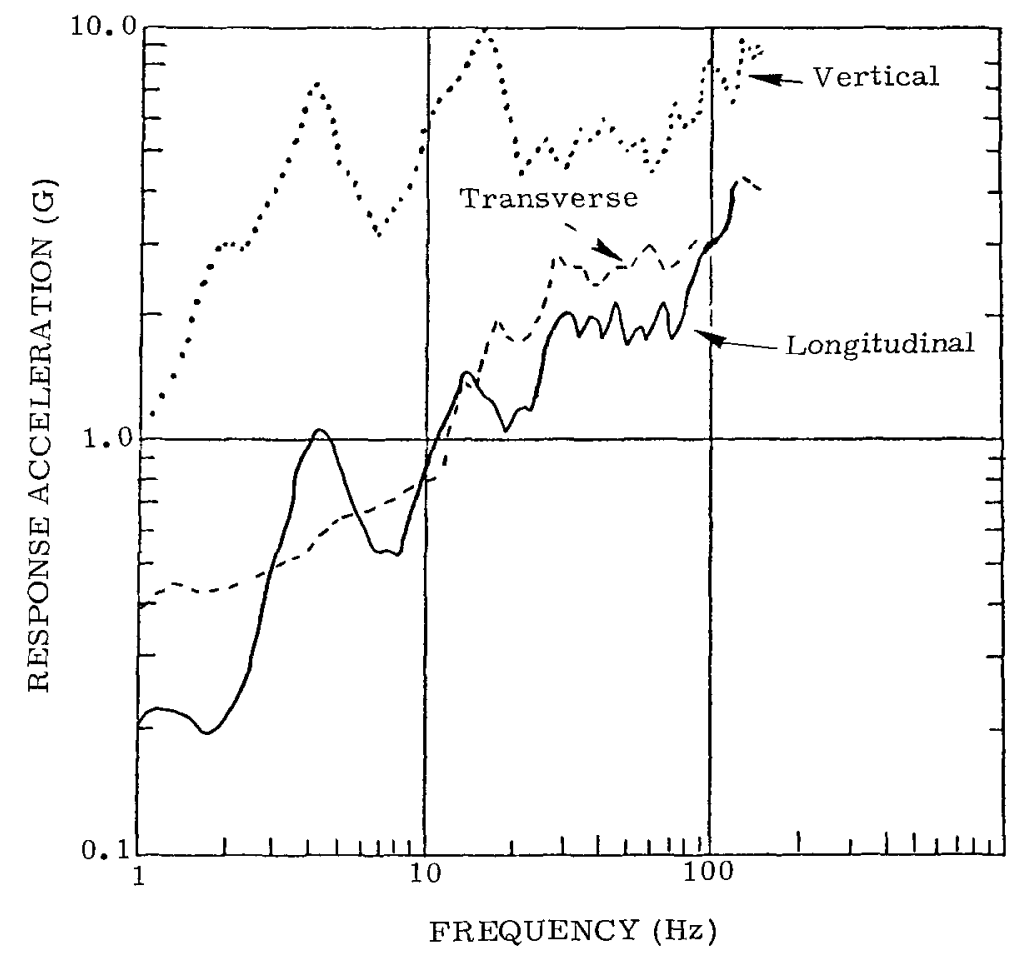

Figure 13. Typical Maximum Response Spectra to Decaying Intermittent Road Shocks-3 Percent Damping

How about short-term environments? The current method used to describe both the intermittent and recurrent environments is not to describe the input environment, but to describe the predicted response of an idealized set of cargo systems to these environments. This is the response of a set of single-degree of freedom systems. It is useful to designers if they have a very simple package system design that can be represented by a single mass, spring, and damper, but its use on a rather complex cargo system such as a complete truckload of boxes piled one upon the other is questionable.

Figure 13 illustrates the nature of short-term environments for truck transport. Both intermittent and recurrent environments are lumped together.

To illustrate a design use, assume that one is looking at a cargo system where the weight is the packaged product and the spring is some kind of resilient material such that this cargo system being considered has a natural frequency of first $3 \mathrm{~Hz}$, and then $5 \mathrm{~Hz}$.

If this idealized cargo system has a natural frequency of $3 \mathrm{~Hz}$, this description says the packaged product will see $4 \mathrm{G}$. If the system has a natural frequency of $5 \mathrm{~Hz}$, the product will see $7 \mathrm{G}$. 


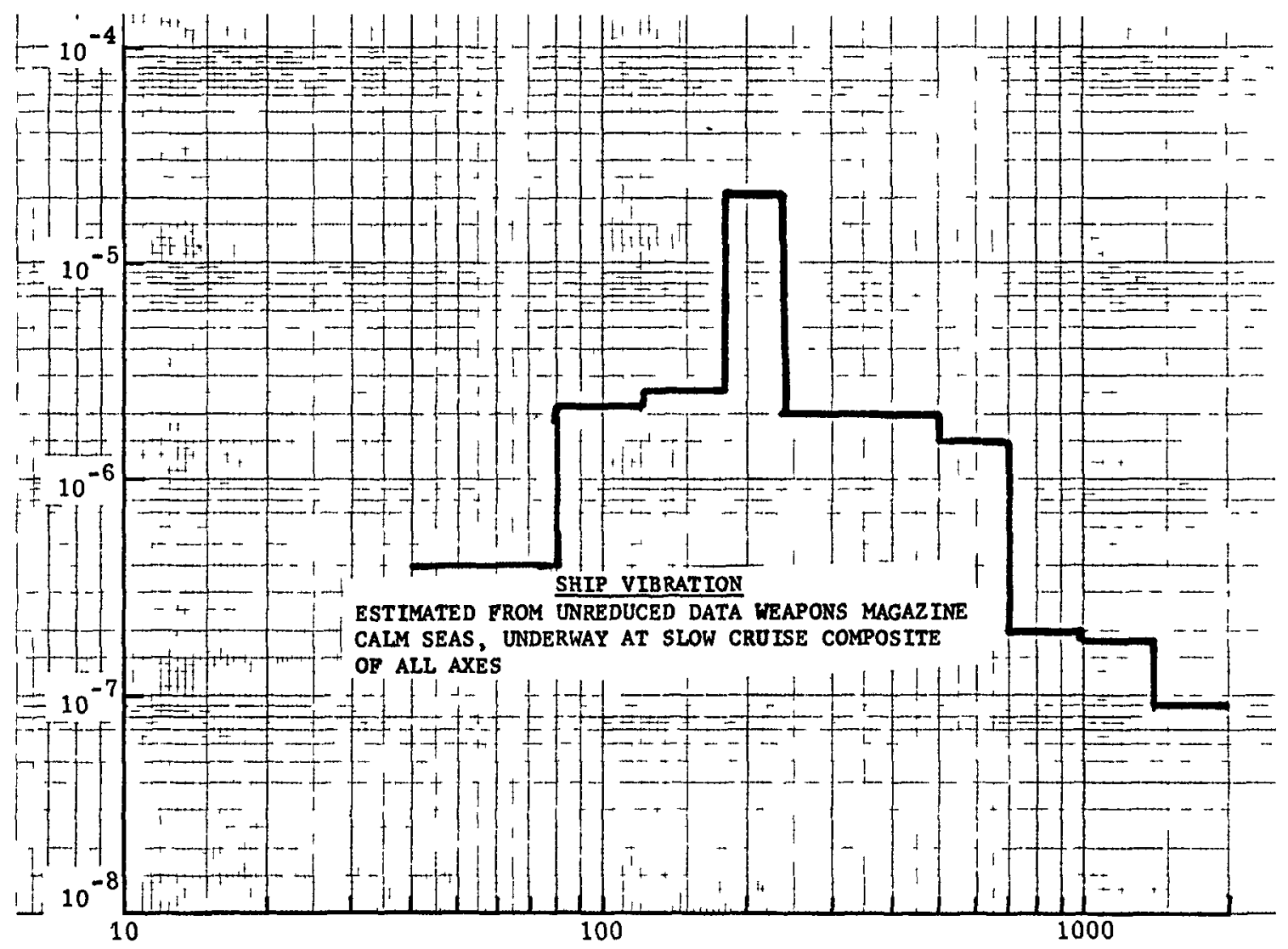

Figure 14. Long-Term Environment for Cargo Ships

Figure 14 shows a long-term environment description for cargo ships. It has been found that the short-term environments except for small craft grounding and beaching is practically nonexistent. Comparison with long-term truck transport environment shows that this is an order of magnitude lower. 


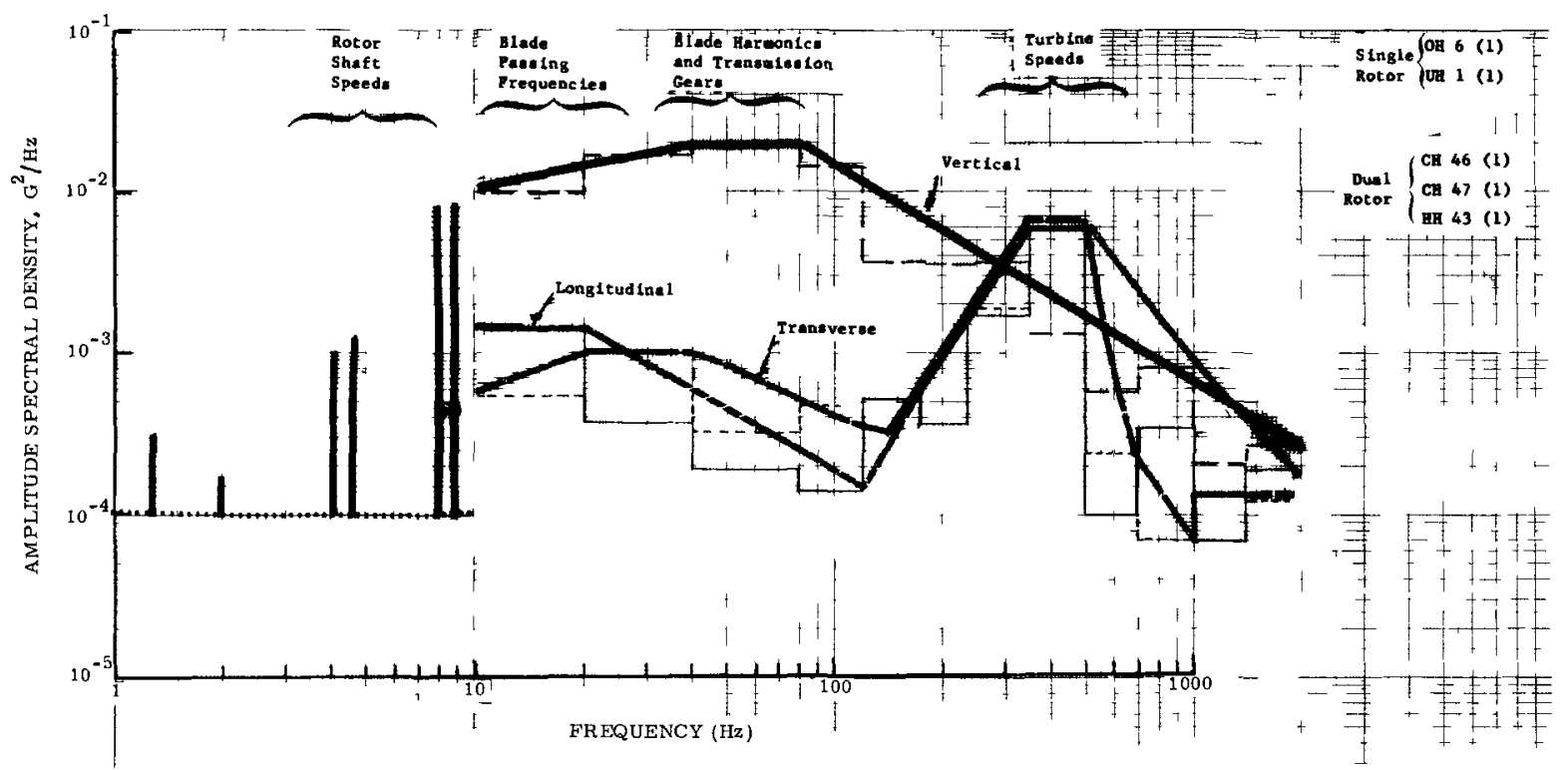

Figure 15. Helıcopter

In Figure 15 is shown a picture of long-term helicopter environment and also included, the presence of a recurrent environment occurring below $10 \mathrm{~Hz}$, the production of decaying sinusoidal motion at discrete frequencies depending upon the shaft speed and number of blades on the rotors. This action is also taking place at frequencies above $10 \mathrm{~Hz}$ within the long-term environment picture. 


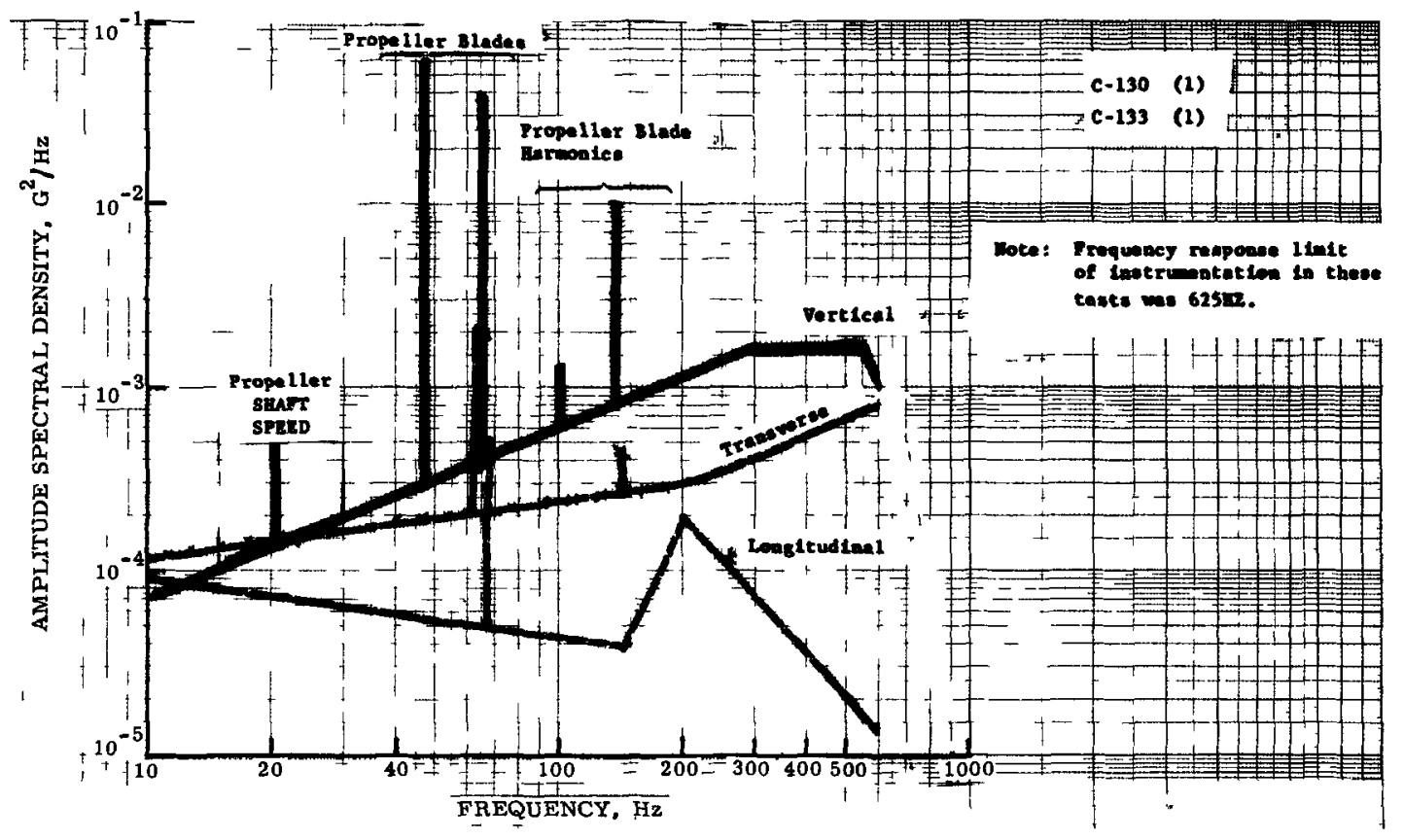

Figure 16. Turboprop Cargo Aircraft (Takeoff)

Figure 16 defines turboprop aircraft takeoff--note that in this environment a superimposed recurrent environment rising above the long term environment. It is produced by propeller shaft speeds and propeller blade passing frequencies. 


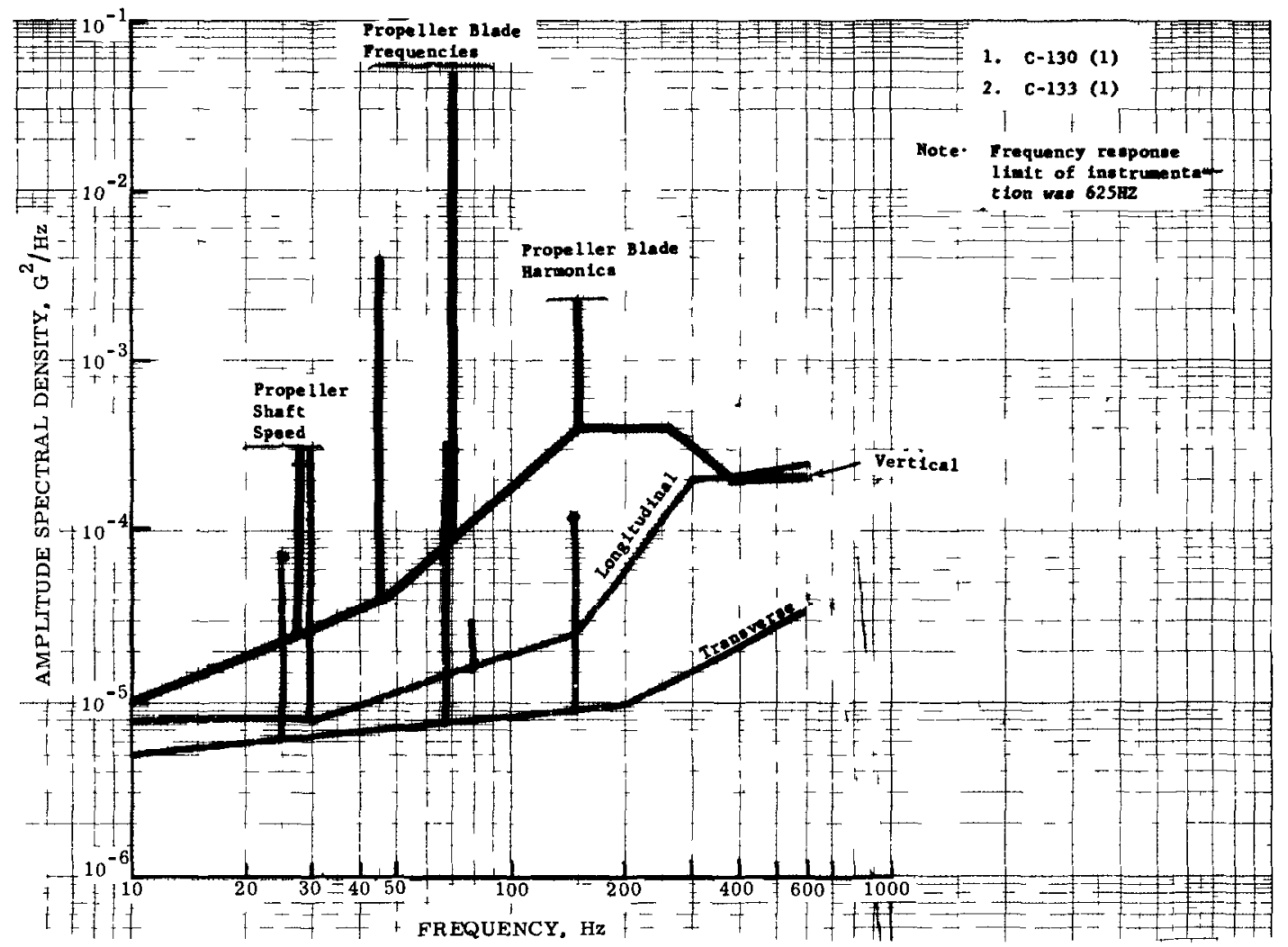

Figure 17. Turboprop Cargo Aircraft (Cruise)

In Figure 17 is a second picture of turboprop cargo aircraft environment. There are two significantly different long-term environments in this mode, that produced by takeoff, climb, and descent, and that produced during cruise. An interesting thing we find in comparing these two long-term environments is the switchover in axis ds-anance between the two events. 


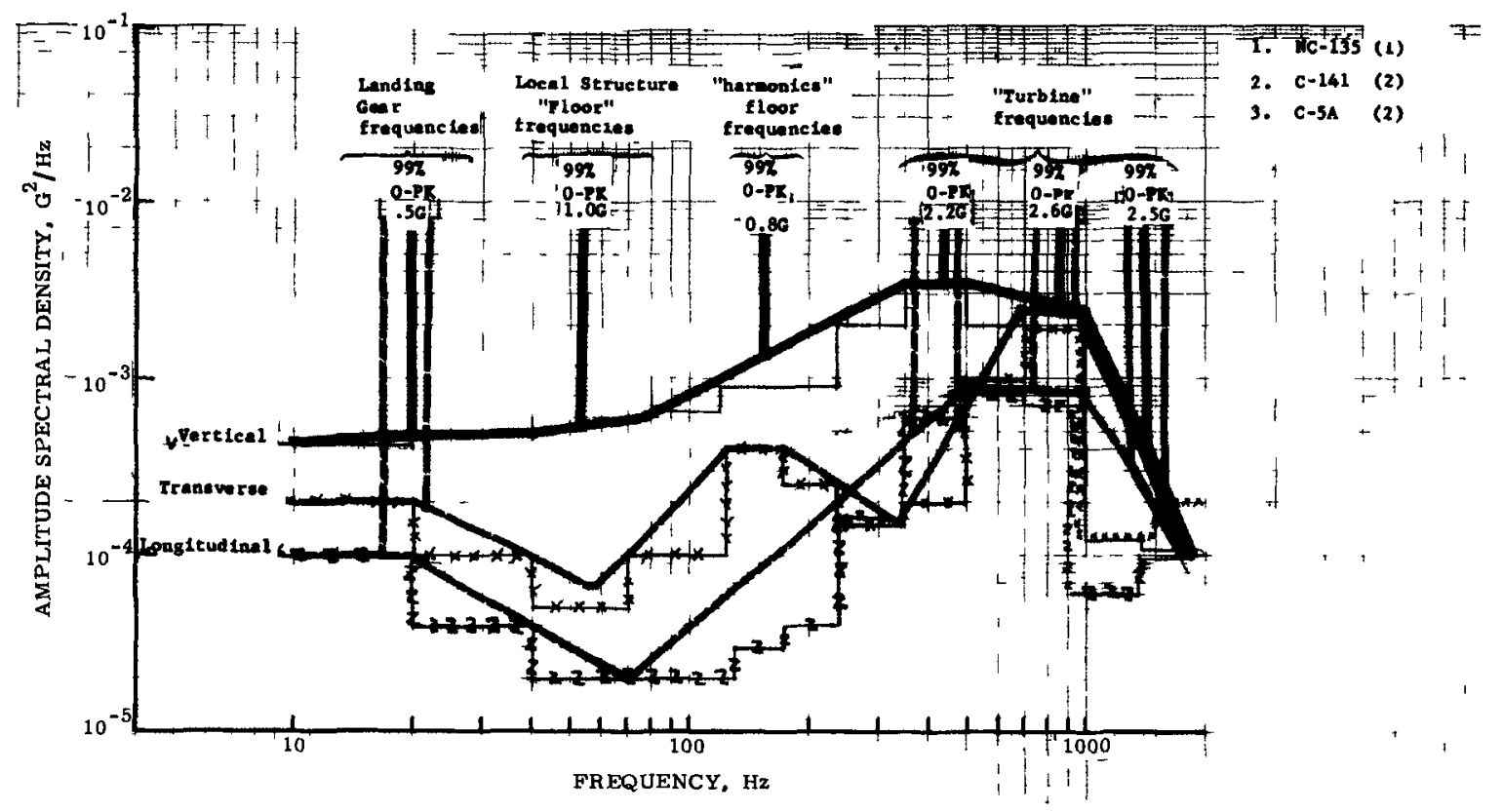

Figure 18. Turbojet Cargo Aircraft (Takeoff/Climb)

Turbojet cargo aircraft takeoff/climb environment is shown in Figure 18. Note the absence of propeller spikes at the lower frequencies and the presence of a new contributor, the jet engines. Some of these recurrent "spikes" are nearly constant amplitude apparently produced by turbine unbalance. Some of these spikes have varying amplitude at discrete frequencies, apparently associated with variation in sirflow within the turbines. 


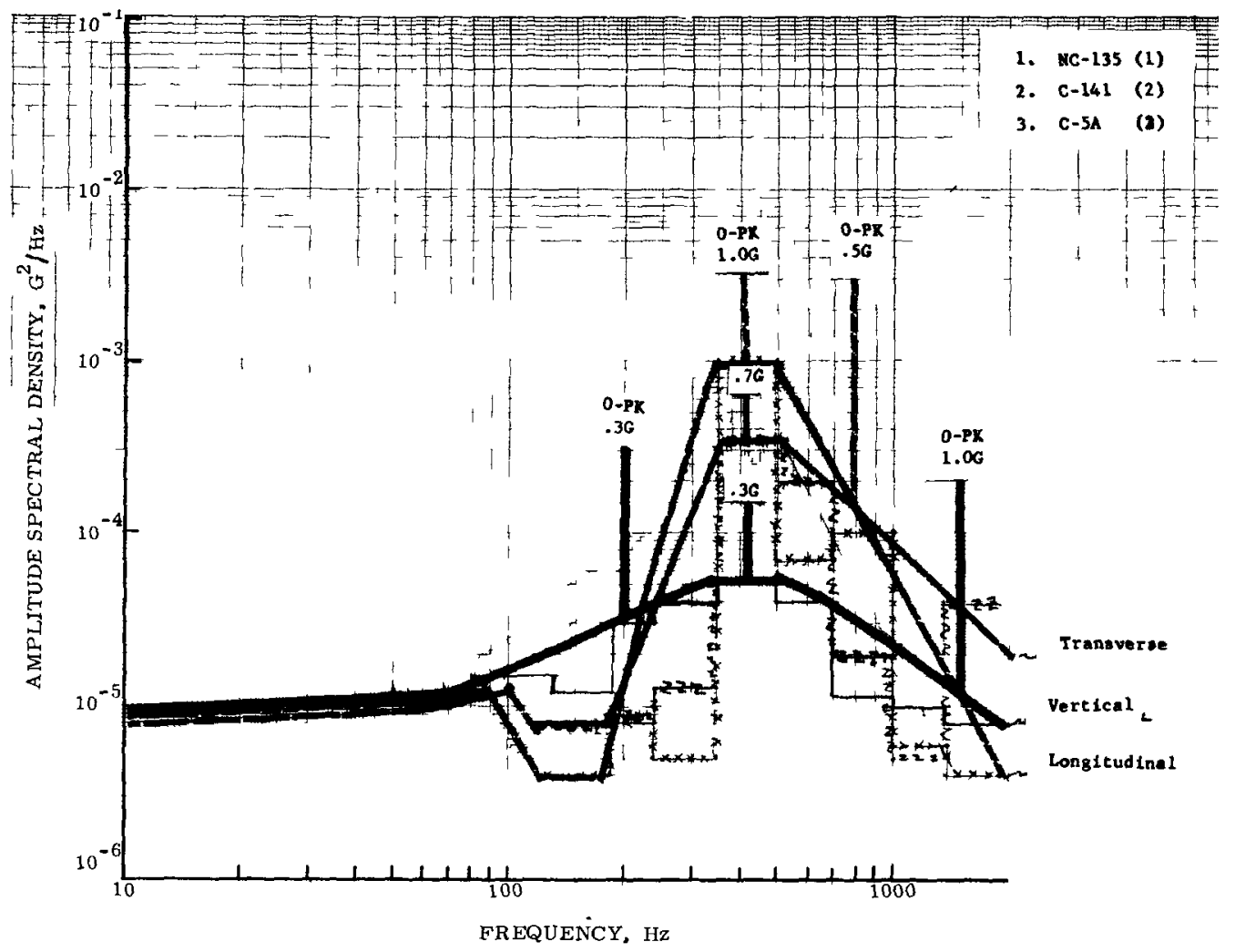

Figure 19. Turbojet Cargo Aircraft (Cruise)

Here (Figure 19) is cruise environment; again, there is a changeover in dominance of activity in the axes of the aircraft.

With regard to the intermittent environments in the air mode of transport such as landing, touchdown, roll-out, and turbulence, the data obtained to data indicate that its damage potential is significantly less than that produced by surface transport modes.

Describing the motion of the vehicle floor is only half of the environment story. With these motions being contributed by different size masses within the vehicle, consider that at each of the frequencies in these motion pictures, that in reality, a different force is being produced at the vehicle bed.

Experiments have been performed to obtain measurements of the force being contributed at each frequency at the bed of these cargo modes to supplement the measurements of motion that have been taken over these many years. The result of one of these experiments on a truck is shown in Figure 20. 


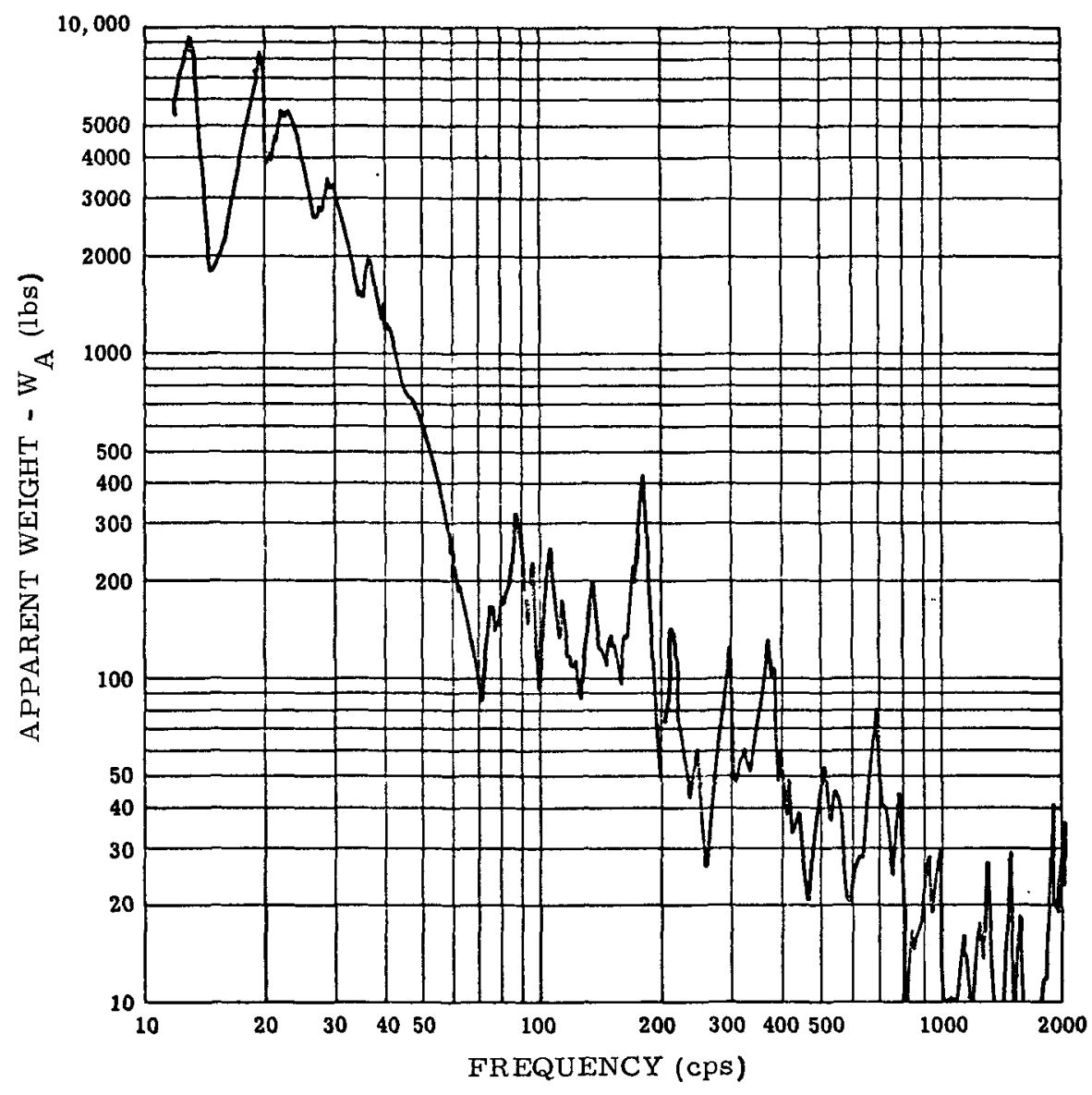

Figure 20. Trailer, Point A (No Cask) - Apparent Weight

Figure 20 is a plot of the force produced by an unloaded truck at the truck bed for one $\mathrm{G}$ of acceleration motion produced at the truck bed. This can be read as follows:

With one $\mathrm{G}$ motion of the truck bed at $10 \mathrm{~Hz}$, the bed will deliver a force of 5000 pounds to anything sitting on that truck bed.

With one $\mathrm{G}$ motion of the truck bed at $100 \mathrm{~Hz}$, the bed can only deliver a force of 100 pounds to anything sitting on that truck bed. 
To summarize what was shown at the presentations:

1. Environment descriptions for use by designers are becoming more complex.

2. This complexity is required when more sophisticated design and evaluation techniques are applied to package system designs.

3. Present day efforts in environment description improvement are centered about predicting vehicle bed motions in a statistical manner. This allows a designer to take a risk-oriented approach to determining design criteria.

4. Future efforts in environment description improvement should be centered about associating the motion descriptions that have been developed with the forces that are produced by these motions. 


\section{FRELILACHS MDOTHLR SOURCES}

Thooletical Tacis yround

1. Shuet and Vibrution Mandbon, Vols I through MII, Ldited by C. M. Harris and C. L. Crede,

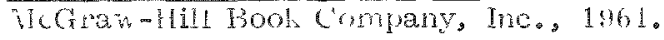

2. Bendat, J. S., and Pirsol, A. G. Voasurement and Aralysis of Random Data, John II iley and Sons, The., 1366.

s. Themson, W. T., Vibration Theory and Apulications, trontice-llall, Ine., 1965.

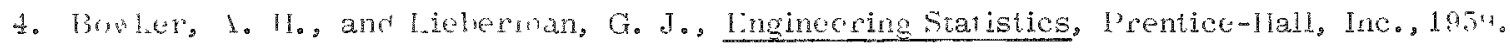

Published Data Solnces

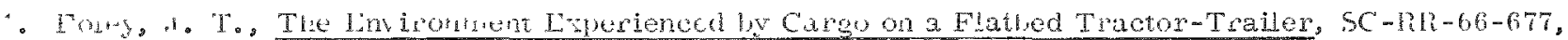
$\operatorname{lig}:$ ?

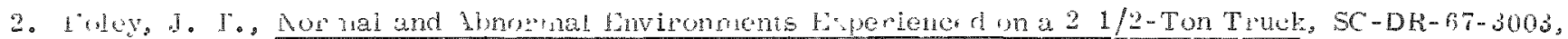
lingio

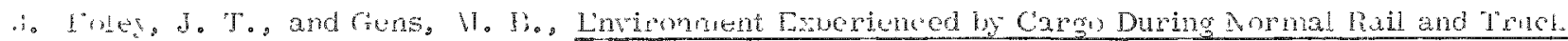

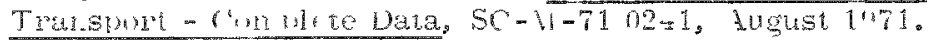

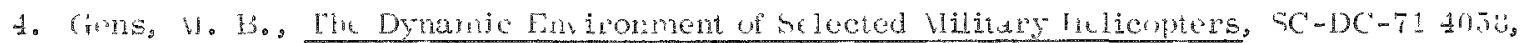
visubers $10 \%$

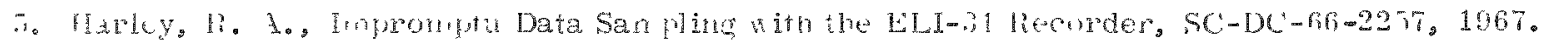

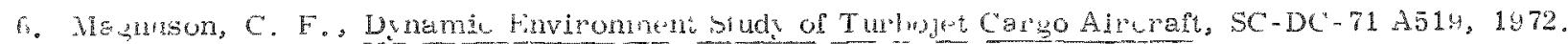

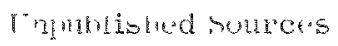

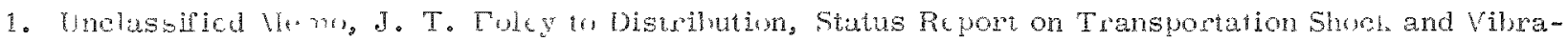

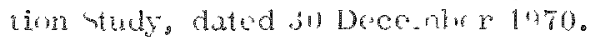

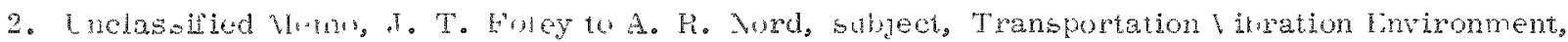
()

\section{I'resentations}

1. Foley, J. T., I - Techniques for Vieasuring Transportation and IIanding Lnvironments; II - Avalable Jiterature and Iow It Vay JuL Package Designers, SC-VI-70-26f, June 1970.

2. Holug. I. T. Applicarion of Lmironmental Data to Test Vethods - Dernvation of Test Levels. $S C=11-601-397,1 \times 396$ 
APPENDIX 
CURRENT PREDICTIVE MODELS OF THE DYNAMIC ENVIRONMENT OF TRANSPORTATION* By: J. T. Foley, M. B. Gens, and C. F. Magnuson, Sandia Laboratories

Abstract

This paper describes the current predictive models of the transportation dynamic environment which have been developed for use by Sandia Laboratories. The information sources, methods of building the models, and the method of representation are described. Advantages and limitations of the models are discussed. Suggestions are given for further work to improve the models.

The Authors

J. T. Foley is Technical Project Leader of the Environmental Criteria Group located within the Criteria and Heat Transfer Division at Sandia Laboratories. Over the past 20 years, his engineering experience has been in the fields of missile flight test, data reduction/analysis, laboratory environmental test, systems development, and environmental operations analysis.

His education includes undergraduate work at Northwestern University. Sacramento State College, and a BSME degree from the University of New Mexico.

He has participated with AEC, DOD, DOT, and NASA yroups engaged in developing siandards for environment, design, and testing.

Mark B. Gens is a member of the technical staff of the Environmental Criteria Group of the Criteria and Heat Transfer Division, Sandia I aboratories, Albuquerque, New Mexico. He has been active in the development of environmental criteria to support the design and test functions at Sandia. A member of IES, he has presented papers at several of the Annual Technical Meetings as well as at the Shock and Vibration Symposium and International Symposium on the Packaging and Transportation of Radioactive Materials. He holds a Master's degree from the University of Toledo, Ohio and has taught in the public schools of Ohio. He joined Sandia as a packaging engineer in 1956 and joined the Environmental Criteria Group in 1966.

C. $F$. Magnuson is a member of the technical staff of the Environmental Criteria Group located within the Criteria and Heat Transfer Division at Sandia Laboratories in Albuquerque, New Mexico. Over the past 20 years his engineering experience has been in the fjelds of design, development, test planning and evaluation, and environmental analysis.

He was graduated from the University of Nebraska with a BSME degree. He is a licensed professional engineer in New Mexico.
Introduction

The purpose of this paper is to present models which predict the dynamic environment experienced by cargo during transportation. These models have been developed from various data sources by the Environmental Criteria Group of Sandia Laboratories as a part of performing the function of providing environmental descriptions to Sandia design and test engineers.

\section{Types of Transportation}

The transportation types considered in the paper are surface transport and air transport. Surface transport includes road, rail, and sea modes. Air transport encompasses turboprop, turbojet, and helicopter aircraft. Individual predictive models for each mode are presented.

General Characteristics of the Dynamic Environment

The dynamic environment of transportation is complex. It may be described as a mixture of continuous excitation with superimposed discrete excitation. The continuous segment is composed of one or more of three types of excitation:

a. Broad-band excitation with amplitudes distributed in a near-Gaussian manner (broad-band random). Example: spectrum caused by the operation of a rocket engine.

b. Single-frequency excitation with amplitudes distributed in a near-Gaussian manner (narrow-band random). Example: excitation caused by the action of a vehicle suspension system.

\footnotetext{
This work was supported by the U.S. Atomic Energy Commission.
} 
c. Single-frequency, constant-amplitude excitation. Fxample: excitation caused by turbojet rotor imbalance.

The idenifiahle discrete excitations usually have high amplitudes and are discontinuous in time. The discrete segment is composed of two trpes of o.citation:

a. Recurrent - which infers periodicity. Example: the response of a truck passins over the joints on a concrete road.

b. Intermittent - which infers a single occurrence or irregularity in occurence. Fxample: the response caused by rail switching or a truck crossing railroad tracks.

Figure 1 illustrates the differences between the two yeneral types of dynamic enironment.

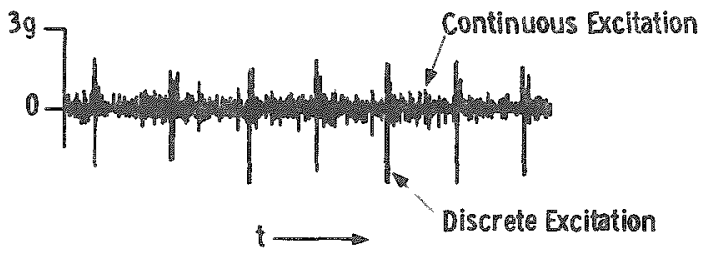

Figure 1. Continuous an Discrete E aitation

Factors which provile mother eomplication aie:

a. There ustally, are tho ur mort alistribut tions of continuons txatation in the same data record.

b. Discrete escitation is oflen superimposed upon continuous excivation.

c. Various types of excitation are of ten intermixed to the point that they axe difficult to isolate one from the other.

In many cases, these conditions may rusult in erroneous judyment as to the amplitude of continuous excitation. Figure 2 is a representation of the results of an analysis of a record of excitation of a composite of railroad dynamic environment. Two separate distributions are apparent. The Caussianlike broad-band distribution invulved approsimately 99 percent of the peaks reported and another dis. tribution was found in the upper 1 percent of the peaks. The noteworthy point, however, is that the upper distribution may occups as much as $60 \mathrm{per}-$ cent of the total range of amplitule found in a frequency band. The upper distribution appears to be produced by evenus which are recurrent and diswete in nature and should not be considered to reppesent the amplitude of continuous excitation.
Further work will he necessary to identify and analyze the upper 1 percent.

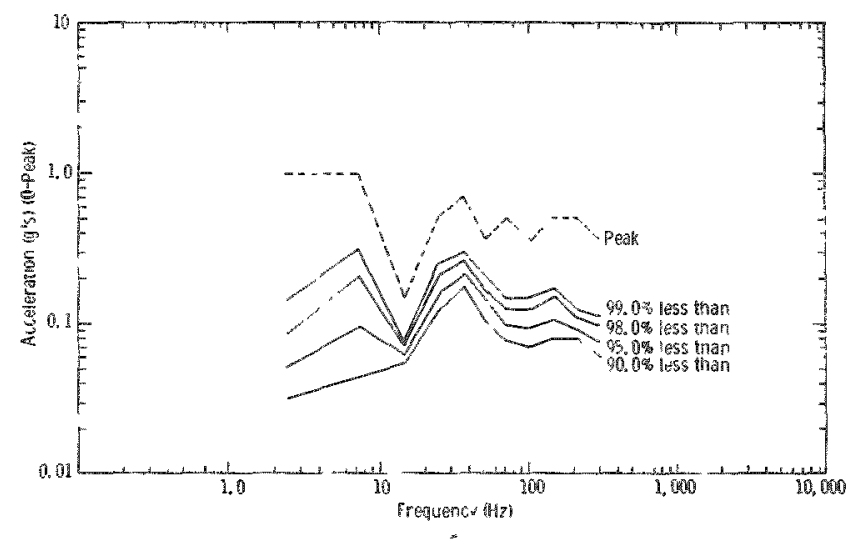

Figure2. Presence of Different Distributions in Data Rerorl (Adapled from ReP. 31)

\section{Predictive Morlel Definition}

For the purposes of this paper a model is defined as a doscription of expected acceleration amplitudes versus frequenes derived from measured data. Thus, a predietive model is a description of an enviromment which mas, be used to predict the level of a specipic enviromment wich may be encountered at a giren frequenc? or in a frernungy band. In all of thr models prasented hesein, level of enviromment is given as zero to peak acceleration.

\section{Trpes of Predictive Models}

The predirtive morteis prosented in this paper arpo of three types:

1. Representative

2. Knvelope

3. Distributive

The representative model is a presentation of a particular event with the intent of characterizing the environment that may occur during all similar events. The utility of this type of model depends heavily upon the judgment used by the data analst to select the rypical event and the manner in which the ustr employs it. The representative type of predictive model is based on a small amount of data and is used only when there is insufficient information to derive a statistical base morlel. It is the least definitive of the model types used, and is, at best, a low confidence prediction of the expected environment.

The envelope ty pe of predictive model usualiy reflerts on! the masimum intensity level that has 
been measurted. Historically, it is the "standard" methud of describing the dy namic environment. Its use "ubaily results in a "urot-cabe" picture.

The listributive ty pe of predictive model is based on statistical analysis and combining of individial data records. It reflects not only the hishest ampitude levels expected in the enrironment, but the distribution of other amplitudes benean the hiphest levels. It requires a large amount of data as a base and a great doal of computational work to prodke it.

In order to make the distributive models most uswiul, they are presented as the $1-0$ occurience levels. This permits a risk-oriented approach to their use. Since the distributive models represent only uata which approach a Gaussian or normal distribution, an discrete or continuous singlefrequency excitation which is preseni should be removed prior to the anals sis necessary to malse the model. A major portion of the upper 1 percent of the peaks has been so identified and removed. IIonever, an ideal method of identify ins and removing such data from within the backyround near Gaussian data remains to be found. We have chosen, therefore, to point out the frequencies at which such exeitations seem to exist by use of aprows at the appro.imate frequency at which thes occurs.

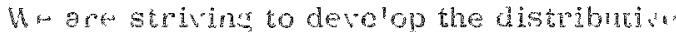
model as our standari for portraying the environment. Whe sufficient data are availahle to permit aciequate analy sis, the predictive models given in this paper are of the astributive type. For completeness, several of the representative and envelope ty pes are also included when sparseness of data makes it inadvisablu to attempt distributive modeling techniques.

Predictive models are not static in nature. Auditional data may cause modification in them, as may the introduction of newly designed vehicles, or new methods of operating older vehicles. The models contained in this study are, as the title implics, consistent with current knowledge, current data, and current vehicles and their methods of usage.

\section{Sourees of Model Data}

\section{Representarive Model Data}

Data for representative type predictive models were senerally obtained from published information which had been stored in the Sanda Environmenial Data Bank. This modeling technique was used only When the amount of data was deemed insufficient to provide a basis fur applving one of the other techniques. Its major use in this paper is to point out areas where further work is required to provide a more definitive description of the dynamic environment.

\section{Envelope Model Data}

The data for envelope type predictive modeis were obtained rom many sources. Envelopins was used in cases where statistical procedures could not be used, either because of a lack of the distributive format in available data or berause of the type of ereitation which was beiny analyzed. In cases of discrete excitations, single degree of freedom response spectra were determined to be the most useful means of presentation and these are not susceptible, as yet, to the degree of combination that may be applied to distributive data. Lnveloping is presentiy the only means available for combining this type of data. The enveloping technique also is a means of developing a model from continuous data which is expressed only in peak amplitude values. The prineipal disadvantage of the envelope model is that it gives no indication of the expected amplitude distribution beneath the envelope. It is, pechaps, overls conservative.

\section{Disiributive Model Data}

Wuch of the data used to develop the predictive models of the distributive type were measured by the Environmental Criteria Group. While some distributive data were available both in the literature and prom mpublished sources, ulir bak ing of additional data provided several advantages:

1. Detailed data, rather than published, pictorial summarizations made it possible to perform numerous statistical tests and analyses.

2. All data were taken on the cargo floor and represented inputs from the vehicle to the load. This discrimination was not always possible in published data.

3. All data were obtained with the same instrumentation and recording system. This provided a commonality which many feel to be essential to minimize the effects of instrumentation variation and subsequent erroneous conclusions.

4. Data reduction was accomplished in the same manner for all records. This permitted direci comparison and application of further computer combinations of the data.

When comparable daca were a zailable from published sources, they were used, at least as a comparison with the Sandia data. A listing of the published data sources used in this manner is given in the bibliography. 


\section{Predictive Models for the \\ Surface Transportation Environment}

Surface transport may be by truck, railroad, or ship. Models for each of these are presented. The predictive models for the continuous environment truck and rail transport are the distributive type, based on a large amount of data and are presented with some degree of confidence. The model of the continuous environment for sea transport is based on detailed data taken only at one point on one ship during slow cruising conditions in calm seas. Further information is required before confidence in a predictive model for sea transport is high.

\section{Truck}

The dynamic environment input to cargo during truck transport has both continuous and discrete portions. The continuous portion is dominant in frequencies above $10 \mathrm{~Hz}$. Figure 3 shows the model which has been developed to picture this environment. The model was based on data measured at the cargo floor of seven different configurations of trucks and tractor-trailer combinations. Both conventional suspensions and air-cushioned suspensions are represented. Detailed information is given in References 2 and 5 through 13 in the bibliography.

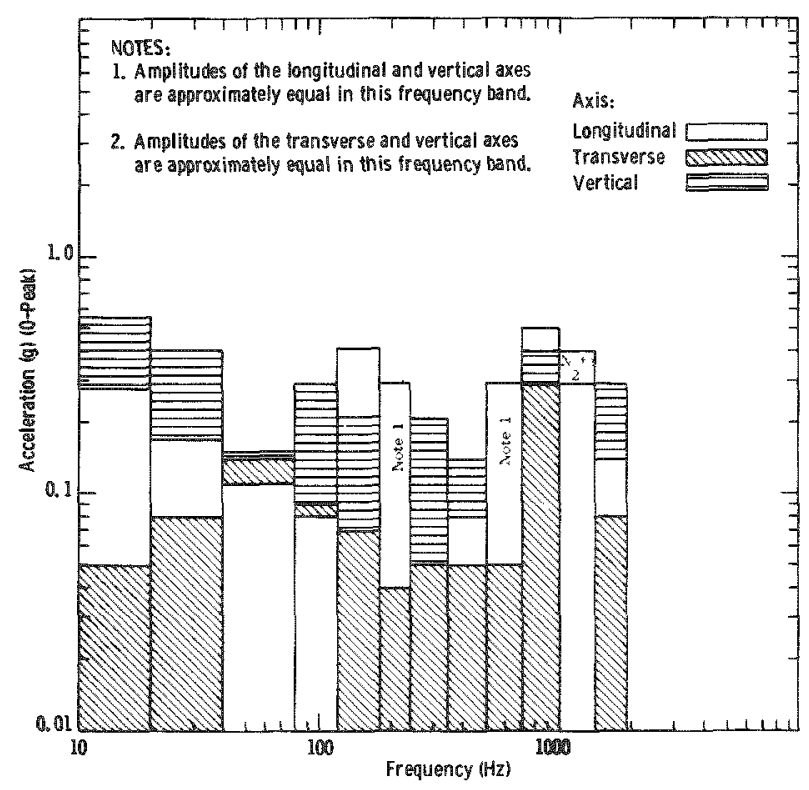

Figure 3. Truck Transport Distributive Model 1- $\sigma$ Level (Continuous Broad-Band Excitation)

Continuous excitation in truck transport generally dominates the surface transport picture. Within this mode, the vertical axis is dominant except in the 120 to $180 \mathrm{~Hz}$ band and 700 to $1000 \mathrm{~Hz}$ band where the longitudinal axis takes precedence. In general, the transverse axis has the lowest amplitudes.
The frequencies below $10 \mathrm{~Hz}$ are dominated by discrete excitations, which also appear superimposed upon higher frequency random excitations. Figure 4 shows a representative model of these phenomena in the form of a series of response spectra envelopes. While these spectra are shown extending to $100 \mathrm{~Hz}$, the area above $10 \mathrm{~Hz}$ is a representation of the absolute peak values of singlefrequency data while those data under $10 \mathrm{~Hz}$ are the best representation of the low frequencies that are available.

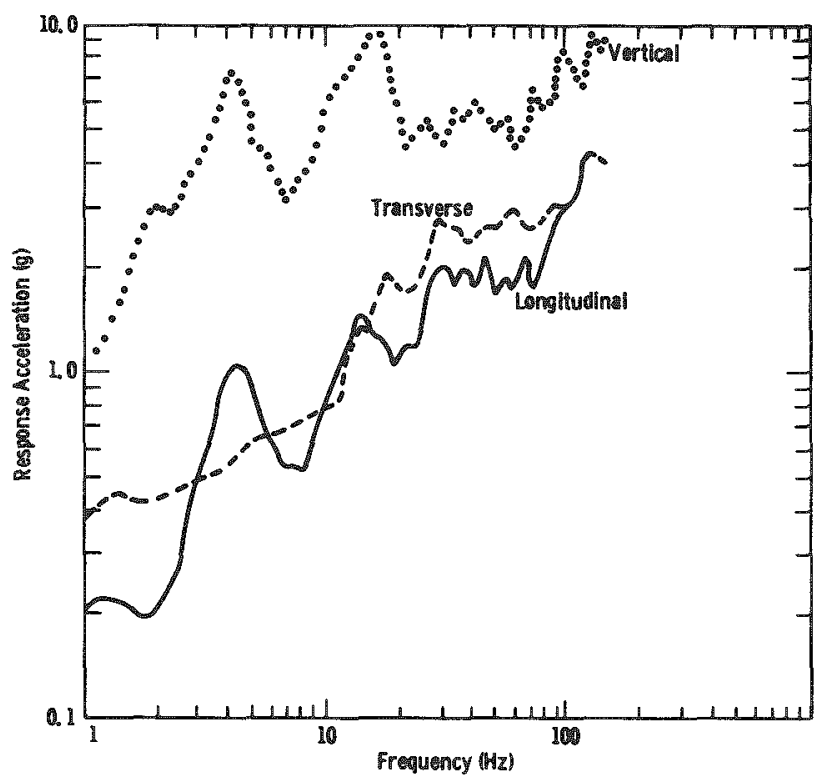

Figure 4. Truck Transport Envelope Mode1 Peak g Response Spectra (Continuous Single Frequency and Discrete Excitation)

Four major sources of excitation have been identified in trucks: the natural frequencies of the suspension system, the tires, the motive system, and the frame members. The suspension system provides the relatively high amplitude, decaying intermittent input at 3 to $6 \mathrm{~Hz}$. The tires excite recurrent accelerations somewhere between 15 and $25 \mathrm{~Hz}$. The engine and drive train cause continuous excitation in the 60 to $80 \mathrm{~Hz}$ band while the frame members are stiff enough to respond at 100 to $120 \mathrm{~Hz}$ in a continuous manner.

\section{Railroad}

The continuous excitation experienced during rail transportation is somewhat lower in amplitude than that experienced in road travel. Figure 5 is a distributive model based on measurements of three rail trips as well as published data. Twenty-two events have been summarized. Data were available only to $350 \mathrm{~Hz}$, but indications were that the amplitudes had reached a plateau at that point. Again, the highest amplitudes were reached generally in the vertical axis; however, excitation in the 
transverse axis is equal or slightly higher in the bands between $60 \mathrm{~Hz}$ and $125 \mathrm{~Hz}$. The longitudinal axis has the lowest continuous amplitude.

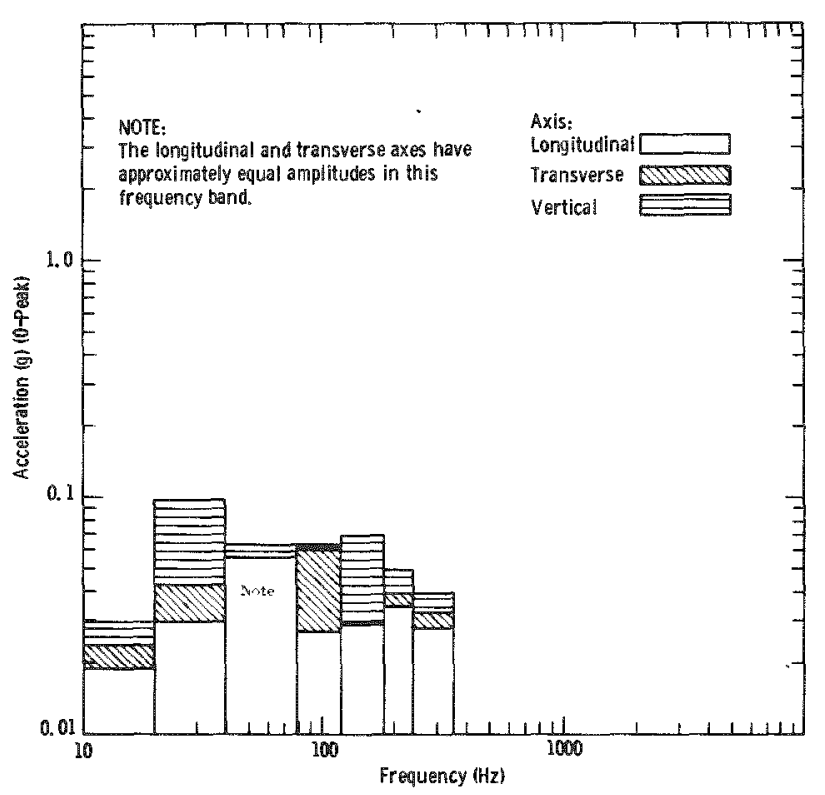

Figure 5. Rail Transport Distributive Model 1- $\sigma$ Level (Continuous Broad-Band Excitation)

Below $10 \mathrm{~Hz}$, the rail environment is best characterized by a response spectrum of representative intermittent accelerations as shown in Figure 6. Above $10 \mathrm{~Hz}$, the peak values of discrete excitation are shown. The major areas of excitation in rail transport include again the suspension system ( 5 to $10 \mathrm{~Hz}$ ), the car frame $(60$ to $100 \mathrm{~Hz}$ ), as well as the excitation produced when traversing track joints ( 10 to $30 \mathrm{~Hz})$. The effect of the suspension system is evident in Figure 6.

In general, the continuous rail environment is less severe than that produced in truck transport. The single event which produces the highest discrete amplitude response in surface transport is rail switching. The response spectrum for this activity is shown in the envelope in Figure 7. The envelope covers a series of measurements and all axes. Note that the amplitude scale on this plot is 2 orders of magnitude higher than is found in the preceding spectra.

\section{Ship}

The dynamic environment of sea transport is not well defined. Available data indicate very low amplitudes of continuous excitation as shown in Figure 8. It is a representative model. Other published information in the Environmental Data Bank is not distributive in nature, but describes levels of the same order of magnitude. Prior to the construc-

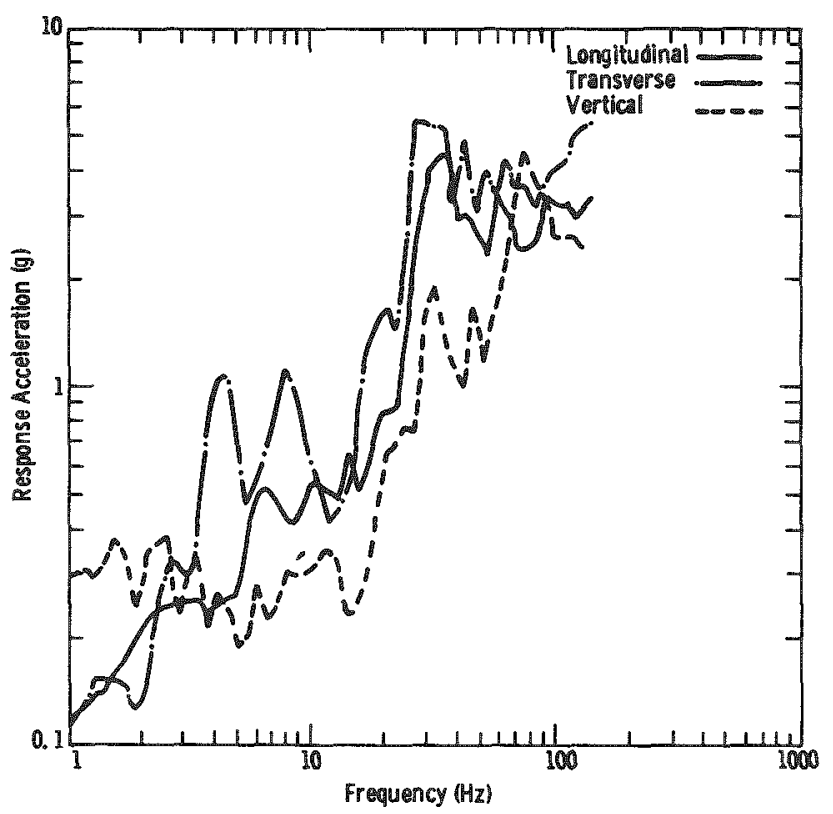

Figure 6. Rail Transport Representative Model Peak. g Response Spectra (Intermittent Discrete Excitation)

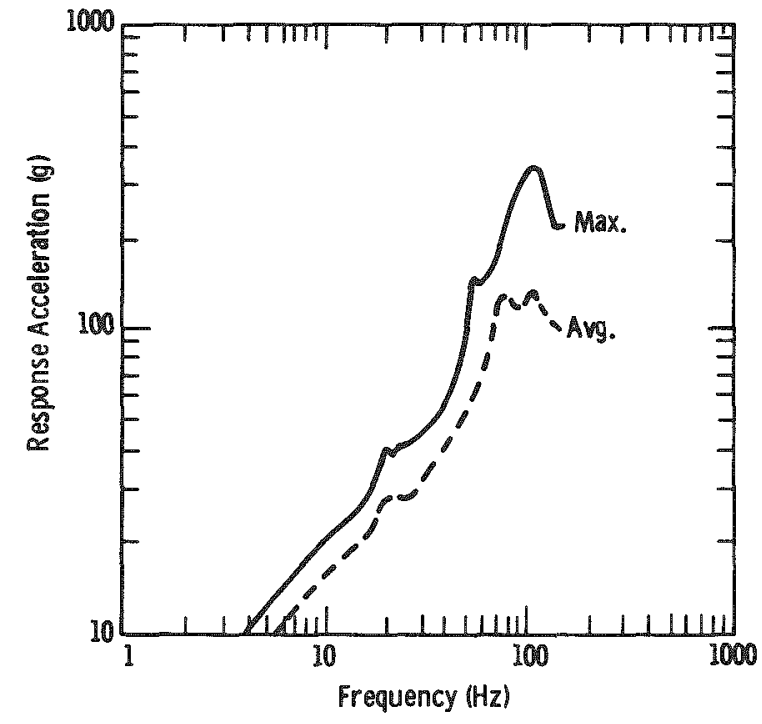

Figure 7. Rail Transport Envelope Model - Peak g Response Spectra (Intermittent Discrete Excitation - Switching)

tion of a distributive model of the dynamic environment of sea transport, additional measurements, under varying sea conditions and for various ship types, should be made. It is evident, however, that the continuous acceleration amplitudes encountered during sea transport are lower than those in other surface modes. References 17 through 23 may be examined for detailed information. 


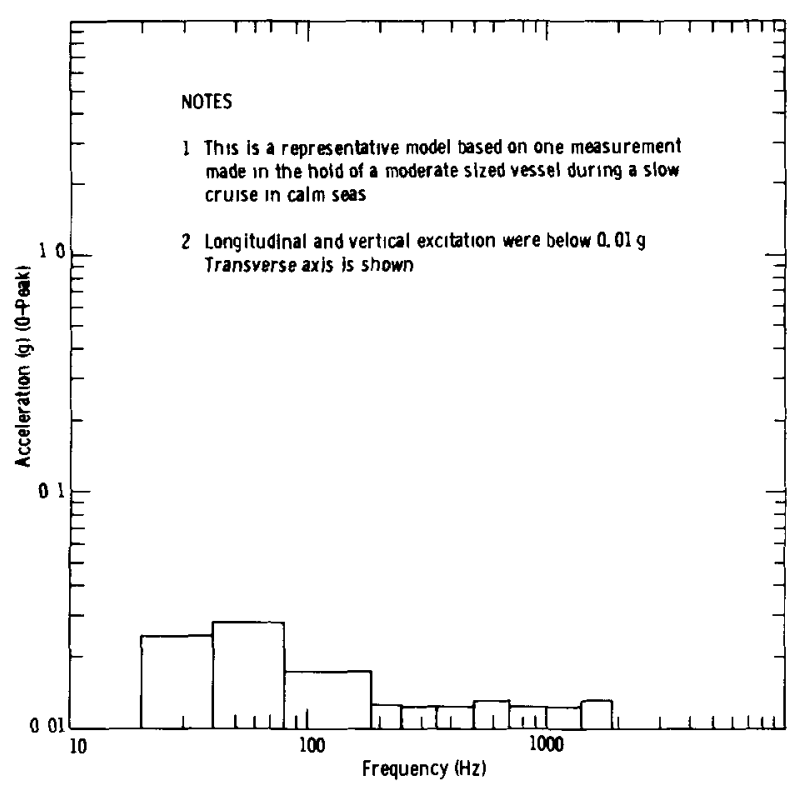

Figure 8. Sea Transport Representative Model 1- $\sigma$ Level (Contınuous Broad-Band Excitation)

Two types of events which may take place during sea transport have not been investigated suff 1 ciently to provide data from which predictive models may be derived: the long-period oscillations caused by swells and wave action and the discrete slamming encountered in rough seas. The long-period oscillations are almost seismic in nature and would probably require instrumentation of a different type than has been used to generate the data for other transport. One of the best discussions of the shipboard environment is given in Reference 31 , but it is limited to peak values and to frequencies under $100 \mathrm{~Hz}$.

\section{Summary of Surface Transport}

The most severe continuous accelerations in surface transport are found in over-the-road cond $1-$ tions. For discrete accelerations of the recurring type the same is generally true, but for intermittent discrete excitations, rall transport is more severe.

Predictive Models for the Air Transportation Environment

Current air transport may be separated into four major categories: reciprocating engine, turboprop aircraft, turbojet aircraft, and rotary-wing aircraft. While the reciprocating engine and the turboprop types are beginning to vanish, some reasonable number of the turboprop alrcraft are still in use, so consideration was given to them. The other types of aircraft are more likely to be employed in the future. Because of the marked difference in dynamic characteristics found in fixed-wing aircraft during the takeoff and climb events and cruise at altitude, these events were considered separately. It should be noted that the time relationship between these types of events is vastly different. In general, the takeoff and clumb events have comparatively high amplitude inputs, which, while generally continuous in nature, are of short duration. Thus they impose high loads for short periods. Inversely, the cruise environment is relatively mild in amplitude, but considerably longer in duration. Another general characteristic of the dynamic environment of aircraft is the presence of continuous excitation of single-frequency accelerations. Depending upon the alrcraft type, these are associated with such activities as shaft speeds, rotor speeds, turbine rotation, and similar mechanical sources. They result in cargo floor motions which are not part of the background Gaussian random excitation. These singlefrequency phenomena usually result in amplitudes which are much higher than the background excitation, but in some cases they cannot be identified separately because they have amplitudes equal to or lower than the Gaussian background.

\section{Turboprop Aircraft}

The source of the data used to develop the predictive models for turboprop aircraft is found in Reference 24. The instrumentation used had a frequency response limit of $625 \mathrm{~Hz}$. Two types of aircraft, the C130 and C133, were measured. The curves shown are distributive models with arrows showing the approximate frequency of the superimposed, single-frequency excitation.

Figure 9 is a model of the acceleration expected during takeoff and climb. The vertical axis is dominant during these events. The longitudinal axis has the lowest amplitudes. It appears that the amplitudes in the transverse and vertical axes are rising at $625 \mathrm{~Hz}$ (instrumentation frequency limit) while the longitudinal axis is falling off, but few of the broad-band Gaussian random accelerations rise above $0.5 \mathrm{~g}$ at the 1- $\sigma$ level. A definite singlefrequency excitation occurs at approximately $68 \mathrm{~Hz}$. This is as high as $1.2 \mathrm{~g}$ (zero to peak) at the $1-\sigma$ level in the vertical axis. Single-frequency indications at lower levels are found in the same frequency in the other axes.

In the cruise mode, shown in Figure 10, acceleration amplitudes are consistently lower than during the takeoff and climb events. Again, the vertical axis is generally dominant except from 350 $\mathrm{Hz}$ to $625 \mathrm{~Hz}$ where the longitudinal axis has amplitudes which are approximately equal to the vertical. During cruise, contrary to takeoff, the transverse axis has consistently low amplitudes. The singlefrequency accelerations at $68 \mathrm{~Hz}$ are again present, rising to $1.5 \mathrm{~g}$ at the $1-\sigma$ level in the vertical axis. Other, lower narrow-band random excitations are also present, but generally at lower levels. In the cruise condition, the amplitude of acceleration seems to reach a plateau at $625 \mathrm{~Hz}$ in all axes. 


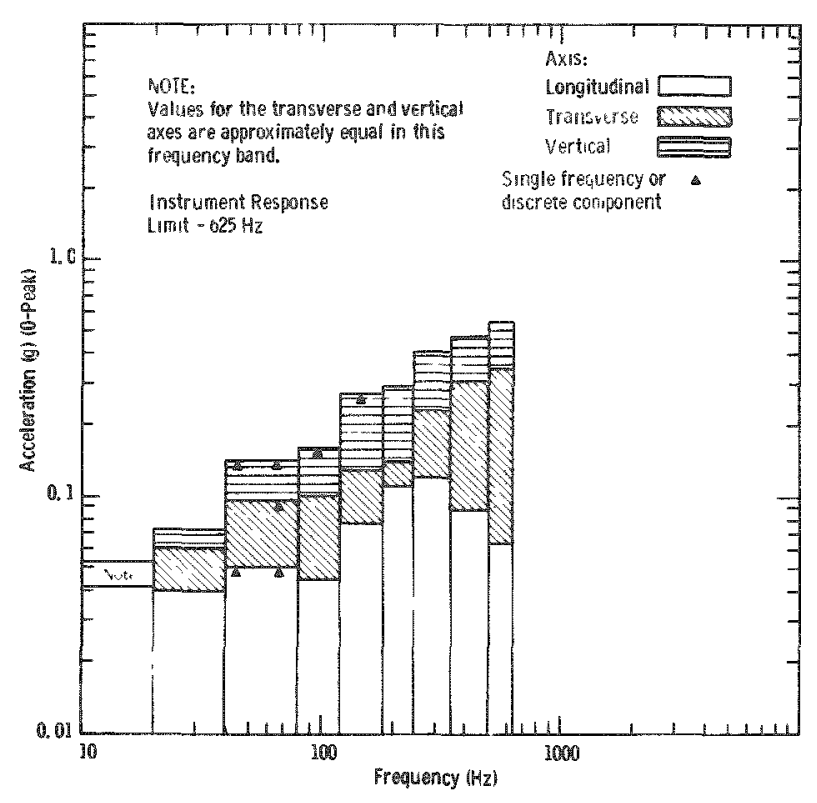

Figure 9. Turboprop Transport Distributive Model - 1-o Level (Continuons BroadBand Fxcitation) Takeoff and Climb

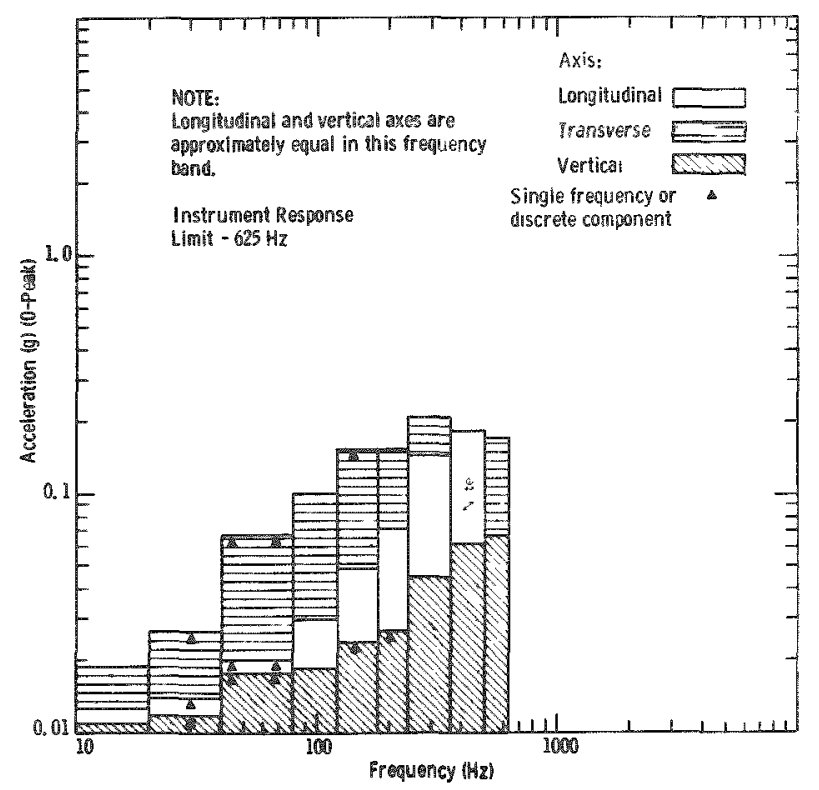

Figure 10. Turhoprop Transport Distributive Model - 1-a Love1 (Continuous BroadBand Excitation) Cruise

\section{Turbojet Aircraft}

The data used to develop the predictive models for the dynamic environment of turbojet aircraft are found in References 25 and 26 . Aircraft included in the measured data are the NC135, C141, and C5A: a total of four aircraft were measured. The data are presented as distributive models with arrows showing the approximate frequencs of superimposed, single-frequency excitation.

The model given in Figure 11 is that of the talooff and climb events for turbojet aircraft. In general, there is a continued upward trend in amplitude levels from $20 \mathrm{~Hz}$ to $1000 \mathrm{~Hz}$ and a falling off of amplitude subsequent to $1000 \mathrm{~Hz}$. The vertical axis is dominant throughout, except in the $700 \mathrm{~Hz}$ to $1000 \mathrm{~Hz}$ frequency and where the transverse gains temporary ascendency. The longitudinal axis exhibits the lowest amplitudes of the three. Continuous single-frequency excitation is superimposed upon the broad-band Gaussian random base at sevtral points, but predominantly above $500 \mathrm{~Hz}$ in all ares.

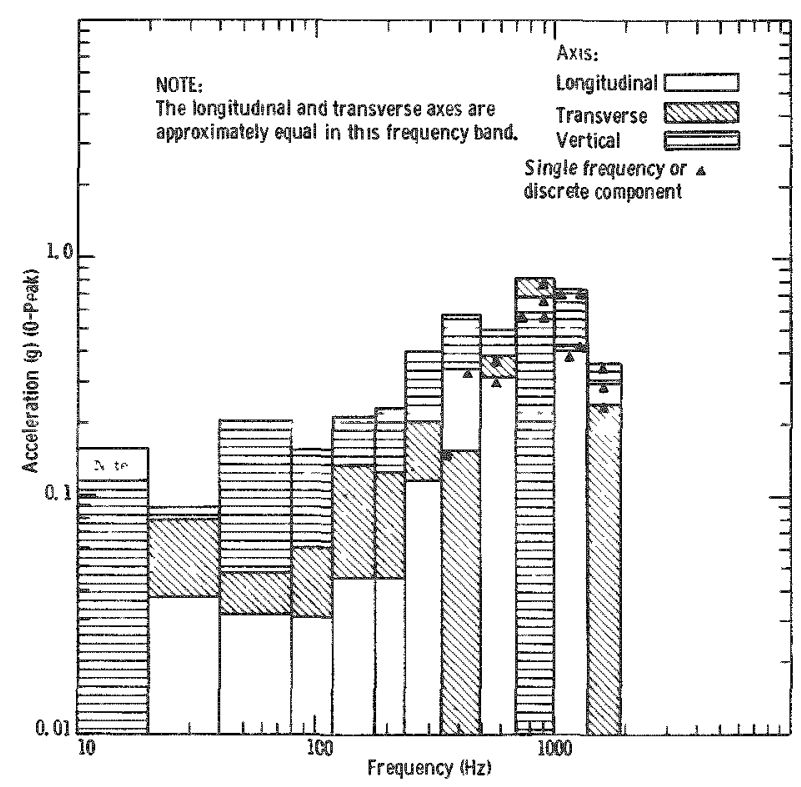

Figure 11. Turbojet Transport Distributive Model - 1-o Level (Continuous BroadBand Excitation) Tukeoff and Climb

Measurements made during cuise at altitude are shown in Figure 12. Once again there is a trend towards a continued rise in amplitude from $20 \mathrm{~Hz}$ to $1000 \mathrm{~Hz}$ and a decline thereafter. Axis domination, however, is not clearcut under these conditions. The vertical axis dominates from $40 \mathrm{~Hz}$ to $240 \mathrm{~Hz}$, but the transverse and longitudinal axes have equal or higher amplitudes in the upper frequencies. The general amplitudes under cruise conditions are lower than during takeof and climb. The superimposed, single-frequency, continuous excitation is found within the same frequency range as in the takeoff events, but at lower amplitudes and it does not appear in the transverse axis. 


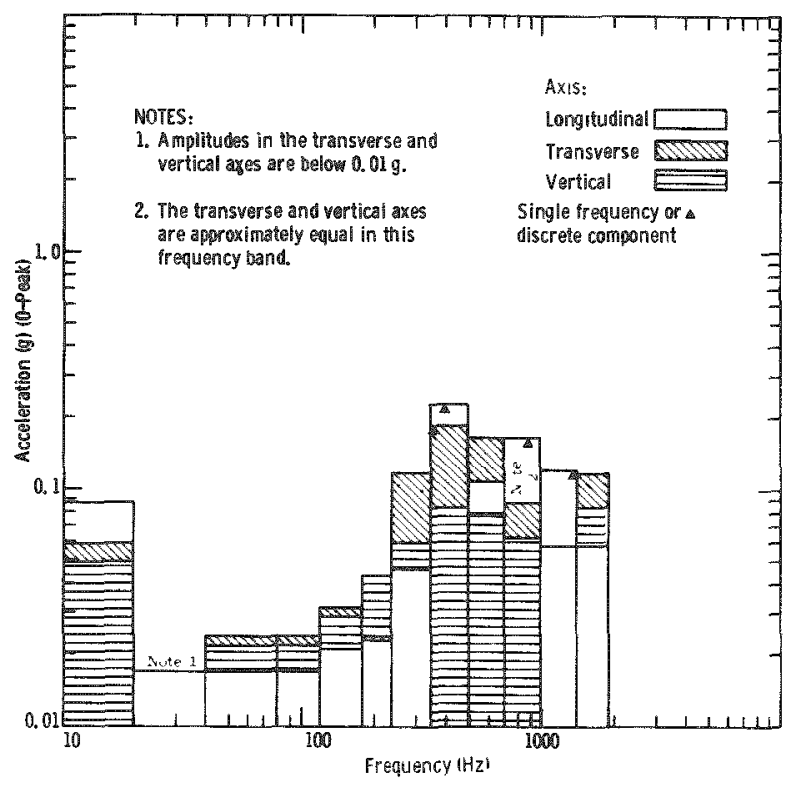

Figure 12. Turbojet Transport Distributive Mode1 1-o Level (Continuous Broad-Band Excitation) Cruise.

\section{Rotary-Wing Aircraft}

The dinamic environment of helicopters is different from that of fixed-wing aircraft. Not only is there little difference between takeof $f$ and cruise. but amplitudes are generall higher, the nearGaussian random components of the excitation are mixed completel with single-frequency rocurring components, and there is significant single-irequenex excitation in the very low frequencies. The data used to develop the models shown are found in References 3, 4, and 27. The models are distributive in type. They represent measuroments from two single-rotor and three dual-rotor aireraft. The single-frequency components of the excitation are not shown separately, since the are intermixed rather than superimposed and are not susceptible to identification as to maximum amplitude or exact frequency. As a result, while an adequate amount of data was available for analysis, the statistical oparations which have been used have yielded models which may not be as useful as was true of the prior distribution models. Because of the increasing importance of the helicopter as a short-haul cargo carrier, the models are presented as the best suidance presently in existence for this environment.

The distributive models for holicopters are shown in Figure 13. The longitudinal and transverse axes are very similar in shape and amplitude in most frequency bands with the transverse axis generally of greater amplitude. The highest amplitudes in both of these axes lie between $240 \mathrm{~Hz}$ and $500 \mathrm{~Hz}$. The amplitudes in the vertical axis are almost ineritably higher. This is true at all frequencies, except from $350 \mathrm{~Hz}$ to $500 \mathrm{~Hz}$ where the

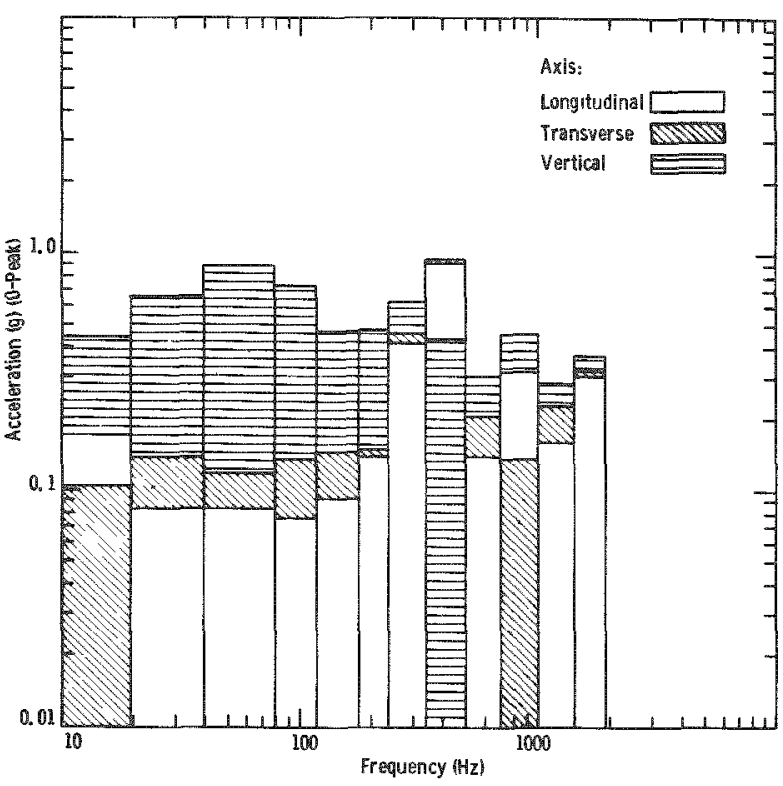

Fisure 13. Helicopter Transport Distributive Vodel - 1-o Level (Continuous BroadBand Ex(itation)

amplitude is hisher in the longitudinal and transverse axes. The excitation in the two horizontal axes rises to a peak between $350 \mathrm{~Hz}$ and $500 \mathrm{~Hz}$ and then essentially levels off to $1900 \mathrm{~Hz}$. In the vertical axis, however, the peak falls between $40 \mathrm{~Hz}$ and $80 \mathrm{~Hz}$ and there is a general derline in amplitude out to $1900 \mathrm{~Hz}$.

In the very low frequencies, under $20 \mathrm{~Hz}$ there are easily identifiable single-frequency, recurring excitations for individual helicopters. A representative model of this type of environment is shown in Figure 14. This type of excitation is presont in all axes, but is most severe in the longitudinal. and transverse axes where peaks as high as $1.4 \mathrm{~g}$ (zero to peak) have been measured.

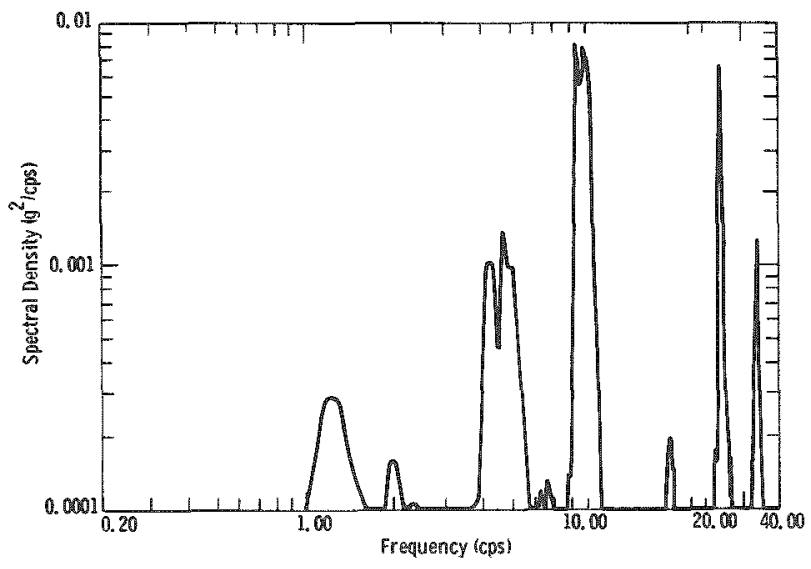

Figure 14. Helicopter Representative Model (Continuous Single-Frequency Excitation) 


\section{Aircraft Transport Summars}

In general, the helicopter presents the most se. ere dyamic nuputs in air transport. High amplitudes in low frequencies are inevitably present as discrete frequency inputs. The overall continuous excitation is very complex and of generally higher amplitude than that of other cargo aircraft.

\section{Conclusions}

We find the dynamic environment in the transportation environment to be complex. In our method of description it consists of a base of near-Gaussian, broad-band, random, continuous excitation with many 1 pes of discrete excitations either superimposed or intermixed with it. The discrete inputs may be recurring at somewhat regular intervals or may be intermittent in nature.

During surface transport, the excitations with highest acceleration amplitude of the continuous and diserete recurrent type are found in truck transport, but the highest intermittent discrete excitation deselops during rail switching. The helicopter presents the most severe continuous environment in air transport.

Generalls, the highest acceleration amplitudes of excitation are found in the rertical axis, but the other axes gain dominance of ten enouyh in specific frequene, bands to make it nereshars to onsiler them separately.

We feel the models given for truck, rail, turbojet, and helicopter transport are supported by a data base sufficient to permit a fair degree of confidence that they repiesent the environment. The models for sea transport are incomplete as are those for turboprop aircraft. In the latter instance, the rapid obsolescence espected probabit precludes further work, but attention needs to be given to a complete defintion of the sea transport environment.

More detalled work is roquired to identif and analyze the recurrent and discrete excitations which are superimposed or intermixed with the background Gaussian-like excitation before complete models of the dyamic environment found during transportation may be constructed.

No mention has been made of several modes of transportation includins tracked vehicles, aircushioned vehreles, hydrofoils, or vehicles emplozing rotary type enyines. In the unstance of tracked vehicles, work is presently in prouress to develop at least a representative model from available data (see References 28-30). More definitive work is proposed. The other vehicle ty pes mentioned are not yet available for use, but should be measured as soon as practicable, or when the are placed in general service.
The models which have been presented and the additional analysis and research which are required to complete the models will not proside the mosi useful description of the environment without determination of the apparent mass characteristics of the various classes of vehicles. A number of measurements of this parameter of the transport environment have been obtained. An effort is being made to compile these data to derive representative impedance models for these transport vehicle ty pes.

\section{Bibliography}

1. Gens, M. B., "The Environmental Operations Analy sis Function," 1967 Proceedinss, 13th Annual Technical Meeting, Institute of Environmental Sciences, April 1967, p. 31.

2. Foley, d. T., "Preliminary Analysis of Data Obtained in the Joint Arm /AEC/Sandia Test of Truck Transport Environment," The Shock and Vibration Bulletin, Bulletin 35, Part $\overline{5}, \bar{U} . \mathrm{S}$. Navai Résearch Taboratory, Washington, February 1966, pp. 57-70.

3. Gens, M. B., Dynamic Environment of Helicopters - Complete Data, SC-NI-71 0604, Sandia Laboratories, Albuquerque, November 1971.

4. Gens, M. B., "The Dinamic Environment of Selected Military Ilelieopters," The Shook and Vibration Bulletin, Bulletin 42, U.S. Naval Research Laboratory, Washington, December 1971.

5. Mortey, J. I.., Joint Army/AEC/Sandia Test of Truck Transport of Environment, December 7 $17,1964, \mathrm{SC}-\mathrm{D} \bar{R}-6 \overline{5}-278$, Sandia Lakoratories, Albuquerque, August 1965.

6. Foley, J. T. Normal and Abnormal Environments Experienced by Cargo on a Flatbed Truck, SC-DR-67-3003, sandia Iaboratories, Albuquerque, February 1968.

7. Foley, J. T., The Environment Experienced by Cargo on a Flatbed Tractor-Trailer Combination, SC-R R-66-677, Sanda Laboratortes. Albuquerque, December 1960.

8. Bryan, M. E., Transportability Study Coverng Highway Movement of Atomic Energy Commission 15-Ton Nuclear Cask from Wilmington, Delaware, to Aibuquerque, New Mesico, WIEA $R-p o r t 65-4$, U.S. Army, Transportation Engineering Agency, Fort Eustis, Virgmua, August 1965 .

9. Foley, J. T., "An En ironmental Research Study," 1367 Proceedings, 13th Annual Technical Meeting, Institute of Environmental Sclences, April 1967, p. 363. 
10. Foley, J. T., "Normal and Abnormal Dynamic Environments Encountered in Truck Transportation, "The Shock and Vibration Bulletin, Bulletin 39, Part 6, T.S. Naval Research Laboratory, Washington, D.C. March 1969 , p. 31 .

11. Foley, J. T., and Gens, M. B., "Shock and Vibration Measurements During Normal Rail and Trusk Transport." Proceedings, Third International Sy mosium on Pat kaging and Transportation of Radioactive Materials, Richland, Washington, August 1971, p. 905.

12. Foley, J.T., and Gens, M. B., Environment Experienced by Cargo During Normal Rail and Truck Transport - Complete Data, SC-MT-71 0241, Sandia Laboratorics, Albuquerque. August 1971.

13. Foley, J. T., Transportation Shock and Vibration Descriptions for Package Designers, $\overline{\mathrm{SC}-}$ M-72 0067 , Sandia Laboratornes, Albuquerque, April 1972 .

14. Gens, M. B., "The Pail Transport Linvironment." The Journal of Environmental Suiences. Vol. SIII, No. 4, Institute of En-ironmental Seiences, Mount Prospect, Illinois, Jul / August 1970 , pp. $14-20$.

15. Wilson, L. T., unpublished data, Sandia Laboratories, Albuquerque, New Mexjco, 1969.

16. Luebke, R. W., Investigation of 60 Foot -70 Ton Boscar Vibration, FRA-RT-70-26, Department of Transportation, Washington, February 1970.

17. Bailey, F. C., Fretch, D.J., and Lise, N. S. Acquisition and Analy sis of Acceleration Data from the SS WOLVERINE STATE and Long-Term Prediction of Seawas Induced Loads on Cargo, Teehnical Report No. 7877116 , Ofice of Transportation, Department of the Army, Irashington, June 1963.

18. U.S.S. LOS ANGELES (CA135), Vibration Test of Langar Space. Test Report No. $58 \overline{7}-\overline{5} t$, Mare Island Naval Ships ard, Vallejo, California, October 1954.

19. Vibration Survey of the U.S.S. MIDWAY, DTMB690. Darid Taylor Model Basin, Washington, March 1948.

20. Project Hawk Report, Report No. BR-691, Raytheon Missile Systems Division, May 1954.

21. Vibration Trials, U.S.S. PHILIPPINE SEA (CV47), DTMB-G6, David Tay lor Model Basin, Washington, August 1947.
22. Vigness, I., and Hardy, V. S., 'Vibration un Ships," Shock and Vibration Brlletin No. 21, U. .. Naval Restarch Laborator, Washington, November 1953.

23. Messenger, W. DeL M., "Vibrations in Ships," The Transport of Radioar tive Materials. United Kingdom Atomic Energy Anthority. London, January 1962 ,

24. Schlue, I. W., and Phelps, $W . C$. , "A New Look at Transportation Vibration Statistics," Shock and Vibration Bulletin, No, 37, Part 7, U.S. Naval Research Laboratory, Washington, October 1967, p. 19-37.

25. Harley, R. A., "Impromptu Vibration Data Acquisition with the Eli-31 Recorder", 1967 Proceedings, 13th Annual Technical Meeting, Institute of Fnvironmental Sciences, April 1967. p. $83-87$.

26. Magnuson, C.F., 'Dynamic Lnvironment Study of 'Turbojet Cargo Aircraft," 1972 Proceedings, 18th Annual Teehnical $\mathbb{M}$ seting, Institute of Lnvironmental Soiences, Mat 1972.

27. Gens, M. B.. "A Preliminary Observation of the Dynamic Enviromment of Helicopters," 1068 Proccedings, 14th Annual Technical Meeting, Institute of Environmental Sciences, April 1968.

28. Pomonik, G. M., and Tinling, N. G., "Dinamis Environment of the $M 113$ Armored Proponnel Carrer," Shouk and Vibration Bulletin, No. 3s, U.S. Naval Research Laboratory, Lashington, 1964 .

29. Vibration and Shock Linvirunments in Vehicles of the Airborne Minitipurpose Famils, Report OHD 61\%, San Jose, California, Food Machinery and Chemical Corporation. December 1960.

30. Roberts, P. V. "Ilawk Suspension System Performance on M754 Tracked Vehicle," Shock and Vibration Bulletin, No. 41, Part 2, Naval ReSearch Laboratory, Washington, December 1970 , p. $159-169$.

31. Ostrem, F. E, and Libovicz, H., A Survey of Envronmental Conditions Incident to the Transportation of Materials, Final Report, CARD Project No. $1512-1$, Department of Transportation, Office of Hazardous Materials, Washington, October 1971. 
DISI RUBUTIOA:

Chester S. Gaynes

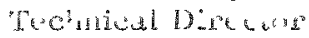

Gaynes Testing Laboratories

1642 Incst Fulton street

Chicago, Illinois 60612

Willian D. Grudshall

rit neral litse aroh Enoinets

Forest Products Laboratory

p.0.130. 31311

Madison, WLeonsin 3370.7

Chartes li. Guerth

Associate Folitor

Paclave Lngineering

S South Wabash trenue

Chicazo, illinois 60808

Paul \%. Grogan

Professor

Department of Lngineering

University Extension

The University of Wisconsin

432 Vorth I al.e street

Vadison, 1 isconsin 53706

James S. Itardigs

Prosident

Iardigs Industries, Ine.

Deerifield, lassachusetts 01342

Janes I. Ilichs

Superrisor

Freight Clatus services

Illinois Central Railroad Company

6327 Dorchestor Avenue

Chicagu, Ilinois 60637

koith O. kellicut

Pruzran Director

Departnent of Engineering

University Extension

The Universitw of Wisconsin

432 North Lake Street

Vadison, Wisconsin 73706

R. Jack Winne

llanager

Pachaging berices

Westinghouse Electric Corporation

Gateway Center

Pittsburgh, Pennsylrania 15222

S. C. Anderson, J $x$.

Senior Vaterial IIanding Engineer

Itunt-12esson Foods, Inc.

164.7 West Valencia Drive

Pullerton, California 12634
Juian $P$. Avelis

luckasing Eingineer

Andrew Corvoration

Inino West $153 \mathrm{rd}$ Street

Orland parh, IIlinois 60462

Franklin Barca

Vechanical Engineer

U. S. Army vatich I ab.

Kansas Sireet

Aatick, Maryland 01760

blan Beiser

Packaging Engineer

Sitchens of Sara Lee

300 Wauhegan Road

Deerfield, ILinois 60015

Lynn Boardman

President

H. L. Boardman, Inc.

$3 \pm$ Vorth Brentwood

Clayton, Missouri 63105

Iobert E: Brandyberry

Packaging Enginees

Duncan Electric Co., Inc.

P. O. Bos 180

Lafayetie, Indiana 47002

Carl Ereitmaier

Pachaying Engineer

Lastman Kodak Co.

"ul Lin Grore Road

Rochester, New York 14650

Alhert Brinkman

Iaclaging Lngineer

Johnson Service Co.

507 Cast Michigan Street

Vilwaukce, Wisconsin 33201

Fred L. Ostren

Rescarch Engineer

General American Transportation Corp.

T449 North Natchez

Niles, Dlinois 60643

George R. Brown

Dewelopment Engineer

Air Force Pachaging Evaluation Agency IVQ.1ELC/DSPED

Wright-Patterson AFB, Ohio 45133

Thonas Burmeister

Senior Packaging Engineer

Travenol Laboratorics

6301 Lincoln Avenue

Vorton Grove, Illinois 60053

Charles C. Carney

Nanager, Packaging Systems

MTS Systems Corp.

1. O. Box 24012

Minneapolis, Nimnesota 35424 
DISTRIBUTION (cont)

G. W. Cook

Packaging Engineer

Bell \& Howell Co.

7100 McCormick Road

Chicago, Dlinois 60645

\section{Lynn Covey}

Supervisor, Classification and Packaging

Diamond Shamrock Chemical Co.

610 Euclid Avenue

Cleveland, Ohio 44114

T. J. Deeren

Chief Packaging Engineer

Owens-Mlinois

P. O. Box 1035

Toledo, Ohio 43601

Gene Ender

Packaging Engineer

Trane Company

La Crosse, Wjsconsin 54601

K. R. Engelmann

Foreman

Electro-NIotive Division, GNIC

P. O. Box 430

La Grange, Dlinois 60525

Robert Fiedler

Packaging Assistant Engineer

UTS Systems Corporation

P. O. Box 24012

Minneapolis, Minnesota 5.5424

Richard Franzen

Lab. Technician

Sealed Air Corporation

3800 West 45 th Street

Chicago, Mlinois 60632

Robert George

Packaging Engineer

Sherwood Medical Industries

11802 Westline, Industrial Drive

St. Louis, Missouri 63141

R. J. Granger

Packaging Engineer

The Procter \& Gamble Company

6110 Center Hill Road

Cincinnati, Ohio 45224

Fred Hallier

Chemist

Chemagro Corporation

P. O. Box 4913

Kansas City, Missouri 64120

Gary Harned

Packaging Engineer

Continental Can

4500 South Kolin

Chicago, Hlinois 60632
Robert J. Haskell - MS 890

Special Systems Department

Westinghouse Electric Corporation

Defense \& Space Center

P. O. Box 746

Baltimore, Maryland 21203

William W. Henderson

Sales

HI. L. Boardman, Inc.

34 North Brentwood

Clayton, Missouri 63105

Donald G. Heydens

Packaging Engineer

CIBA-GEIGY Corporation

Saw Mill River Road

Ardsley, New York 10502

Brian D. Hopkins

Package Engineer

Nlead-Johnson \& Company

2404 Pennsylvania

Evansville, Indiana 47721

Maurice T. Horsman

Packaging Engineer

Control Data

5300 West 76 th

Minneapolis, Minnesota 55435

Joseph M. Huffnagle

Senior Product Engineer

Hol-Gar Division, Yardney Electric Corp.

500 Mildred Avenue

Primos, Pennsylvania 19018

Wayne M. Iultberg

Nanager, Package-Design Development

Travenol Laboratories, Inc.

6301 Lincoln Avenue

Norton Grove, Mlinois 60053

William S. Jewett

Engineer

Eastman Kodak Company

901 Elmgrove Road

Rochester, New York 14650

Gilbert Juern

Packaging Engineer

Victor Gasket Division

Dana Corporation

5750 West Roosevelt Road

Chicago, Mlinois 60650

Ray Jurgens

Design Engineer

Weyerhaeuser Company

2000 South 18th Street

Vanitowoc, Wisconsin 54220 
DISTRIBUTION (cont)

R. L. Kuhn

Development Spec.

Dow Chemical Company

2040 Building

Midland, Miichigan 48640

James $\mathrm{X}$. Law rence

Industrial Packaging Engineer

Digital Equipment Corporation

146 Nain Street

Maynard, Massachusetts 01754

Donald J. Le Beau

Design Engineer

A. O. Smith Corporation

Route 49

Kankakee, Illinois 60901

William C. Manika.

Regional Customer Service

United Parcel Service

1400 South Jefferson Street

Chicago, Dlinois 60607

James P. NcGreevy

Research Chemist.

Chemagro - Division of Baychen Corporation

P. O. Box 4913

Hawthorn Road

Kansas City, Missouri 64120

James S. Morris

Packaging Scientist

Camation Company

8015 ran Nuys BIvd.

Van Nuys, California 91412

Joseph Nueller

Sup. Packaging Engineer

Whirlpool Corporation

Upton Drive

St. Joseph, Nichigan

Raymond J. Odierno

Issistant Director

Pachage Research Laboratory

P. O. Box 127

hockaway, New Jersey 07866

Benjamin Quaintance

Structural Design Manager

International Paper Co., Container Div.

2101 Kansas Avenue

Kansas City, Lansas 66119

Nicolas E. Ramos

Packaging Tech.

Kitchens of Sara Lee

500 North Waukegan Road

Deerfield, Illinois 60015

Robert Favas

Packaging Designer

Carrier Air Conditioning Company

Carrier Parkway

Syracuse, New York 13201
Edward O. Reairdon

Packaging Engineer - Mgr. Structural Design International Paper Company

1601 Las Plumas

San Jose, California 95106

D. H. Reynolds

Engineer Technician

Naval Ordnance Laboratory

White Oak, Room 20-172

Silver Spring, Maryland 20910

A. H. Schottland

Manager

Standard Bent Glass Company

P. O. Box 469

Butler, Pennsylvania 16001

R. F. Sheridan

Eli Lilly and Company

P. O. Box 618

Indianapolis, Indiana 46206

Gilbort G. Slyter

Regional Marine Specialist

Insurance $\mathrm{Co}$. of North America

167 West Jackson Blvd.

Chicago, Illinois 60025

Kenneth E. Smith

Senior Packaying Engineer

Monsanto Company

800 North I,indbergh Blvd.

St. Louis, Missouri 63166

Robert $X$. Stephenson

Assistant to the President

Cherry-Burrell Corporation

2400 Sixth Street, South West

Cedar Rapids, Iowa 52406

James $R$. Strong

Supervisor, $\mathrm{P}^{\mathrm{kg}}$. Design and Material Ilandling Engineering

Micro Switch, Division of Honeywell

11 West Spring Street

Freeport, Illinois 61032

Charles Suttex

Accounting Manager

Weyerhaeuser Company

2000 South 18 th Street

Manitowoc, Wisconsin 54220

Raymond N. Thelen

Package Engineer

Oscar Nayer \& Company

910 Mayer Avenue

Nladison, Wisconsin 53701

N. P. Theophilos

Mlanager of Distribution Engineering

Union Carbide, Linde Division

P. O. Box 44

Tonawanda, New York 14150 
DISTRIBUTION (cont)

William Silver, Senior Engineer Westinghouse Electric Corp.

Product Qualification Laboratory

M.S. 504 - P.O. Box 746

Baltimore, Maryland 21203

WIN 234-2241

\section{Les Albright}

Westinghouse Electric Corp.

Shipping West Building

Baltimore, Maryland

William Albright

Large Power Transformer

23rd and Cowan Road

Muncie, Indiana 47305

George Applegate

Mfg. Engineering, Elevator Div.

150 Pacific Avenue

Jersey City, N.J. 07304

Richard J. Auchter

Assistant Director

Fiber Products Research

Forest Products Laboratory

U.S. Forest Service

P.O. Box 5130

Madison, Wisconsin 53705

John C. Bechtel

Electric Stairways \&

Hydraulic Elevator Division

Supvr. of Material Distribution

Gettysburg, Pa. 17325

R. O. Bender

Supvr. Shipping, Power Systems

700 Braddoch Avenue

East Pittsburg, $\mathrm{Pa}$.

Rodger Bird

Senior QC Engineer

Mansfield Major Appliance

246 E. 4th Street

Mansfield, Ohio

Ernest F. Bock

Westinghouse Industrial Equipment

P. O. Box 300

Sykesville, Md. 21784

James Borghi

Distribution \& Equipment Div.

Tuscaraus Road

Beaver, Pa. 15009

J. B. Bowers

Westinghouse Electric Corp.

300 Phillippi Road

Columbus, Ohio 43228
John Bowron

Manager, Distribution Services

610 Allegany Square

Pittsburgh, Pa. 15212

Paul Boyer

Westinghouse Electric Corp.

Cockeysville, Maryland

Bill Broyles, Manager

Traffic Department

500 Westinghouse Drive

P. O. Box 883

Jefferson City, Mo. 65101

Russ Brown

Distribution \& Equipment Div.

Tuscaraus Road

Beaver, Pa. 15009

William N. Burt

Westinghouse Electric Corp.

Sharon, $\mathrm{Pa}, 44438$

G. H. Calhoun

Packaging Engineer

Small Motor Division

2025 East 4 th Street

Lima, Ohio 45802

Joseph Campbe1l, Test Engineer

Westinghouse Electric Corp.

NFD Monroeville

Monroeville, $\mathrm{Pa}$.

Dr. George C. Carter

Manager of $\mathrm{Mfg}$.

OR\&EC - Oceanic - Box 1488

Annapolis, Maryland

Roy Crews

Computer Instrumentation Division

Pace Controller Packaging

Pittsburgh, $\mathrm{Pa}$.

Spencer G, Duin

Engr. Service Manager

Ind. \& Defense - District Equipment

1601 South Vandeventer Street

St. Louis, Mo, 63110

Paul R. Foley

Westinghouse Electric Corp.

4454 Genesee Street

Buffalo, N.Y. 14240

R. W. France

Supervisor Quality Assurance

Transportation Division

Pittsburgh, $\mathrm{Pa} .15122$ 
DISTRIBUTION (cont)

John H. Fuller

Regional Operation Manager

Distribution Services

1300 Bellmont Avenue

Philadelphia, Pa. 19104

George W. Gillespie, Engineer

Product Transition Lab

$R \& D$ Center

Pittsburgh, $\mathrm{Pa}$.

John J. Gordon, Operations Manager

Home Systems

4300 36th Street, S. E.

Grand Rapids, Mich. 49508

Michael Greeley

Westinghouse Electric Corp.

Industrial Division

543 North Lang Avenue

Pittsburgh, Pa. 15208

Walter Gura, Packaging Engineer Aerospace \& Electronic Sys. Div. P.O. Box 1897 - M.S. 800

Baltimore, Maryland 21203

Robert E. Haley

Facilities Engineer

Distribution Services

W Building - Room 977

Pittsburgh, Pa. 15222

W. J. Hartnett

Nuclear Fuel Division

P. O. Box 5906

Columbia, S.C. 29205

R. J. Herriott

Westinghouse Electric Corp.

300 Phillippi Road

Columbus, Ohio 43228

J. Hicks, Packaging Engineer

District Apparatus

P. O. Box 341

Bloomington, Ind.

Frank Holderbaum

Mgr. Shipping, Rec. \& Traffic

Specialty Metals

R.D. No. 2, Box 45

Blairsville, $\mathrm{Pa} .15717$

Larry G. Hubbard

Manufacturing Engineer

Decorative Micarta Division

Hampton, S.C. 29924
Thomas Jones

Supv. Traffic \& Shipping

Relay and Instrument

95 Orange Street

Newark, N. J. 07101

Eugene Karpowicz

Engineer Design Group

Medium AC

Buffalo, New York

Robert G. Lee, Packaging Engineer Interior Lighting Division

P.O. Box 824

Vicksburgh, Mississippi 39180

Eugene D. Legg, Engineer

Computer \& Instrumentation

O'Hara Township

200 Beta Drive

Pittsburgh, Pa. 15238

R. F. Loudenberg, Jr.

Westinghouse Electric Corp.

Room Air Conditioning Division

Rt. 27 and Vineyard Road

Edison, New Jersey 08817

E. S. Maryniak

Foreman Shipping Department

Power Circuit Breaker

Forbes Road

Trafford, $\mathrm{Pa}$.

Harry Milne

Lima AED

P. O. Box 989

Lima, Ohio 45802

Denis R. Moore

Physical Distribution Consultant

Westinghouse Canada Ltd. Operations

840 York Mills Road - P. O. 510

Hamilton 23 Ontario, Canada

John Muller

Westinghouse Electric Corp.

Gettysburg Elevator Components

Rt. 34 North

Gettysburg, Pa.

J. J. Murphy

Westinghouse Electric Corp.

300 Phillippi Road

Columbus, Ohio 43228

Jack Murphy

Packaging Engineer

Electric Tubes

P. O. Box 284

Elmira, New York 14902 
DISTRIBUTION (cont)

Brian McGraw, Senior Analyst

Westinghouse Canada Ltd.

Switchgear \& Control

606 Aberdeen Avenue

Hamilton 12 Ontario, Canada

\section{Jack McDermott}

Traffic Representative

Urban Systems Development Corp.

3401 Tidewater Trail

Fredericksburg, Va. 22401

Willard M. Pakutka

Westinghouse Electric Corp.

Lamp Division

Bloomfield, N. J.

R. E. Petersen, Engineer

Luxaire, Inc.

West of Filbert Street

Elyria, Ohio 44035

\section{E. J. Price}

Foreman Shipping

Westinghouse Power Systems

700 Braddock Avenue

East Pittsburgh, $\mathrm{Pa}$.

Lloyd Prosser, Assist. Engr.

Crating and Dishwashers

Westinghouse Canada Ltd. Major Appliances

P. O. Box 510

Hamilton 23 Ontario, Canada

J. A. Purcell

Westinghouse Nuclear Fuel Division

P. O. Box 5906

Columbia, S.C. 29205

Rodger Sandefer

Westinghouse Major Appliance

Engr. Service Dept.

Mansfield, Ohio

Martin Schibler

Westinghouse Electric Corp.

P.O. Marine Division M.S. 51-1

Hendy Avenue

Sunnyvale, California 94086

William Sherman

Westinghouse Electric Corp.

P.O. Marine Division - M. S. 51-1

Hendy Avenue

Sunnyvale, California 94086

Walter E. Smith

Westinghouse ESSD

Defense and Electronics Systems Center

Cockeysville, Maryland
Wayne Smitley

Manager Range Engineering

246 E. 4th Street - Dept. A-60

Mansfield, Ohio

R. G. Stein

P. T. L. - R\&D Center

1310 Beulah Road

Pittsburgh, Pa. 15235

Al Stevens

Westinghouse Meter Plant

Box 9533

Raleigh, N.C. 27603

George Stryker

Material Handling Engineer

Westinghouse Lamp Division

1 Westinghouse Plaza

Bloomfield, N.J. 07003

Paul R. Swank, Pkg. Engineer

Westinghouse Home Appliances

Engr. Dept. A-20

Mansfield, Ohio

John Volpe

Mfg. Engr. (Pkg)

Westinghouse Relay-Instrument

95 Orange Street

Newark, N. J. 07028

Paul A. VanMiddlesworth

I. E. Plant Materials Handling

Westinghouse Thermoking Corp.

314 W. 90th Street

Bloomington, Minn. 55420

\section{R. D. Webster}

Westinghouse Electric Corp.

Plant Apparatus Division

Penn Center

Pittsburgh, Pa.

Bernard S. Westerman, Project Manager Manufacturing Development Laboratory

$R \& D$ Center

Pittsburgh, Pa. 15235

Dale White, Design Engineer

Westinghouse Transformer Division

469 Sharpesville Avenue

Sharon, Pa. 16146

W. E. Wilson

Manager, Shipping \& Receiving

Westinghouse General Control

Box 225

Buffalo, New York 14240 
DISTRIBUTION (cont)

Ronald J. Thomaswick Development Engineer

PPG Industries

Glass Research

P. O. Box 11472

Creighton, Pennsylvania 15238

W. Walker

Division Material Handling Engineer

For Motor Company

Transportation Division

36200 Plymouth Road

Livonia, Michigan 48150

Donald Willis

Supervisory Industrial Engineer

Attn: AMXSV/PC

Savannah Army Depot

Savannah, Illinois 61074

Daniel Young

Freight Expediter

Carrier Air Conditioning Company

Carrier Parkway

Syracuse, New York 13201

A. Witte

KAMAN Sciences

1700 Garden of the Gods Road

Colorado Springs, Colorado 80907

Deputy Commanding General

USA MUCOM

Attn: AMSMU-MM

Attn: W. Martin

Joliet, Ilinois 60436

W. A. Gardner, 1500

C. C. Burks, 1511

D. M. Olson, 1514 (Acting)

W. E. Alzheimer, 1517

G. J. Hildebrandt, 1520

C. H. Mauney, 1530

W. R. Reynolds, 1531

T. B. Lane, 1540

S. W. Key, 1541

T. G. Priddy, 1542

B. E. Bader, 1543

R. T. Othmer, 1544

J. T. Risse, 1553

E. I. Bruce, 1554

C. S. Hoyle, 8353 (3)

Attn: C. A. Scott, 8353

Attn: P. H. Prasthofer, 8353

L. S. Ostrander, 8232

R. S. Gillespie, 3151 (2)

W. K. Cox, 3142-1 (15) 